\title{
Environmental Pathology
}

\author{
José A. Centeno, Florabel G. Mullick, Kamal G. Ishak' ${ }^{\dagger}$, Teri J. Franks, \\ Allen P. Burke, Michael N. Koss, Daniel P. Perl, Paul B. Tchounwou, \\ and Joseph P. Pestaner
}

\section{Contents}

25.1 Introduction. 569

25.2 The Skin. 570

25.3 The Brain. 572

25.4 Inhalation Injury. 575

25.5 Cardiovascular System. 580

25.6 Hepatotoxicity of Metal Ions.

Further Reading. 585 592

${ }^{\dagger}$ Deceased

J.A. Centeno $(\bowtie)$

Joint Pathology Center Division of Biophysical Toxicology,

Malcolm Grow Medical Clinic Joint Base Andrews Air Naval Facility,

Washington, DC, USA

e-mail: jose.a.centeno@us.army.mil

F.G. Mullick • T.J. Franks •

A.P. Burke

The Joint Pathology Center Silver Spring, MD, USA

K.G. Ishak ${ }^{\dagger}$

M.N. Koss

Medical Laboratories, University of Southern California Medical Center, Los Angeles, CA, USA

D.P. Perl

Department of Neurology, Uniformed Services University of the Health Sciences, Bethesda, MD, USA

P.B. Tchounwou

College of Science, Engineering and Technology, Jackson State

University, Jackson, MS, USA

J.P. Pestaner

Medical Examiner Office, Washington, DC, USA

\subsection{Introduction}

Humans are constantly exposed to hazardous pollutants in the environment-for example, in the air, water, soil, rocks, diet, or workplace. Trace metals are important in environmental pathology because of the wide range of toxic reactions and their potential adverse effects on the physiological function of organ systems. Exposures to toxic trace metals have been the subject of numerous environmental and geochemical investigations, and many studies have been published on the acute and/or chronic effects of high-level exposures to these types of agents; however, much fewer data are available concerning the health effects of low-dose chronic exposure to many trace metals. Chronic low-dose exposures to toxic elements such as cadmium and arsenic have been shown to cause these metals to accumulate in tissues over time, leading to multiple adverse effects in exposed individuals.

Exposure to toxic trace metals occurs via three principal routes: percutaneous absorption, ingestion, or inhalation. The toxic effects may affect specific target organ components, resulting in immunological-induced injury or specific functional changes. The diseases caused by metals can be genetic or acquired, and the effects can be acute or chronic. This chapter provides a review of some of these pathologies and discusses the critical organ systems that are affected. Examining such toxicities is a medical challenge in that a number of metallic elements, such as iron, copper, and manganese, are essential to life. Distinguishing normal and pathologic states is critical to our understanding of the pathogenesis of metal-induced diseases. The toxic properties of

This chapter is dedicated to the memory of Kamal G. Ishak, M.D. Ph.D. (1928-2004).

The opinions and assertions expressed herein are those of the authors and are not to be construed as official or representing the views of The Joint Pathology Center, the US Department of the Army or the Department of Defense 
certain metals, such as lead and mercury, have been acknowledged since ancient times, but enhanced pathologic analyses have allowed us to learn much about how metals can affect specific organ systems. Also reviewed in this chapter are the pathologic states caused by metals in the skin, brain, lung, heart, and liver.

\subsection{The Skin}

The list of metals exhibiting dermal toxicity has been well catalogued. Such metals include compounds used in medicinal products, industrial processes, pesticides, cosmetics, dyes, and jewelry (Lansdown 1995). Of major concern is exposure to metals and metalloids through contaminated water and other environmental and geological media. Dermal toxicity is a result of local tissue responses to direct contact of a metal with skin or, alternatively, it may represent a manifestation of systemic toxicity following ingestion or inhalation. Allergic contact dermatitis induced by nickel is one such example of a local tissue response. The adverse cutaneous reactions resulting from chronic ingestion or inhalation of arsenical compounds exemplify systemic toxicity.

A variety of pathologic responses in the skin are associated with both acute and chronic exposures to metals. Categorization of these responses presents a challenge to the environmental pathologist, as the histologic features associated with metal-induced skin lesions may mimic virtually any known morphologic skin disease. The more frequently encountered morphologic changes include spongiotic dermatitis (allergic contact dermatitis and primary irritant dermatitis), granulomatous inflammation, pigmentation disorders, and cancer. A pertinent exposure history correlated with pathologic findings should be done to establish a precise diagnosis.

The occurrence of hyper- and hypopigmentation of the skin has been reported worldwide in populations chronically exposed to arsenic from contaminated drinking water (see also Chap. 12, this volume). Because of its widespread presence in the environment, arsenic has become one of the most studied elements in environmental toxicology and public health. The ensuing discussion centers on arsenic and arsenicrelated skin diseases, which are considered by many to be the prototype of the development of disease following exposure to a metal.

\subsubsection{Arsenic and Metal-Induced Cancer of the Skin}

The most widely recognized toxic element affecting the skin is arsenic. Arsenic is the twentieth most abundant element in the Earth's crust. It is odorless and tasteless and exhibits both acute and chronic health effects in humans. In nature, arsenic can occur as metalloid alloys or in a variety of chemical compounds. In geological media such as rocks, arsenic is commonly found as a sulfide such as orpiment $\left(\mathrm{As}_{2} \mathrm{~S}_{3}\right)$ or realgar $\left(\mathrm{As}_{2} \mathrm{~S}_{2}\right)$ in the form of arseno-pyrite or mixed sulfides (AsFeS). Significant amounts of arsenic may also be found bound to gold, silver, copper, lead, zinc, and cobalt ores. Mining of these minerals may result in the mobilization and/or transport of arsenic into drinking water. Arsenic has also been used in a variety of agricultural applications (e.g., pesticides, insecticides), industrial applications (e.g., manufacturing of solid-state detectors), and medical applications (e.g., drugs and medical treatments).

As with all toxic metals, the toxic effects of arsenic are related to the chemical and physical forms in which it appears: metallic, $\operatorname{As}(0)$; inorganic, $\operatorname{As}(\mathrm{III})$ and $\mathrm{As}(\mathrm{V})$; and organic, As(III) and As(V). Although arsenic exhibits both organic and inorganic forms, the inorganic trivalent arsenic compounds are considered to demonstrate the greatest toxicity. The molecular basis by which arsenic compounds may induce their toxicity in humans has been described. Impairment of cellular respiration through inhibition of various mitochondrial enzymes and uncoupling of oxidative phosphorylation is one of the major mechanisms by which arsenic exerts its toxic effects. At the molecular level, the toxicity of arsenic results from its ability to interact with sulfhydryl groups of proteins and enzymes and to substitute phosphorus in a variety of biochemical reactions ( $\mathrm{Li}$ and Rossman 1989). In vitro experiments have demonstrated that arsenic reacts with protein sulfhydryl groups to inactivate enzymes such as dihydrolipoyl dehydrogenase and thiolase, thereby producing inhibited oxidation of pyruvate and beta-oxidation of fatty acids (Belton et al. 1985).

Humans are exposed to inorganic arsenic mainly through the oral and inhalation routes. Direct dermal exposure also occurs, but to a lesser extent. The oral route includes contaminated drinking water, food, drugs (including Chinese herbal medications), and tobacco. Inhalation occurs primarily in occupational settings; workers may be exposed to arsenic in the air as a by-product of copper and lead smelting, pesticide production, manufacturing of glass, and production of semiconductors (Chan and Huff 1997). Arsenic tends to concentrate in ectodermal tissues, including the skin, hair, and nails. Biomethylation is considered the major metabolic pathway for inorganic arsenic in humans. Historically, the enzymatic conversion of inorganic arsenic to mono- and dimethylated species has been considered a primary detoxification mechanism of inorganic arsenic; however, compelling experimental evidence obtained from several laboratories suggests that biomethylation, particularly the production of methylated metabolites that contain trivalent arsenic, is a process that can activate arsenic as a toxin and a carcinogen (Styblo et al. 2002; Wei et al. 2002). 
Fig. 25.1 Arsenic-induced hyperkeratosis of the hands

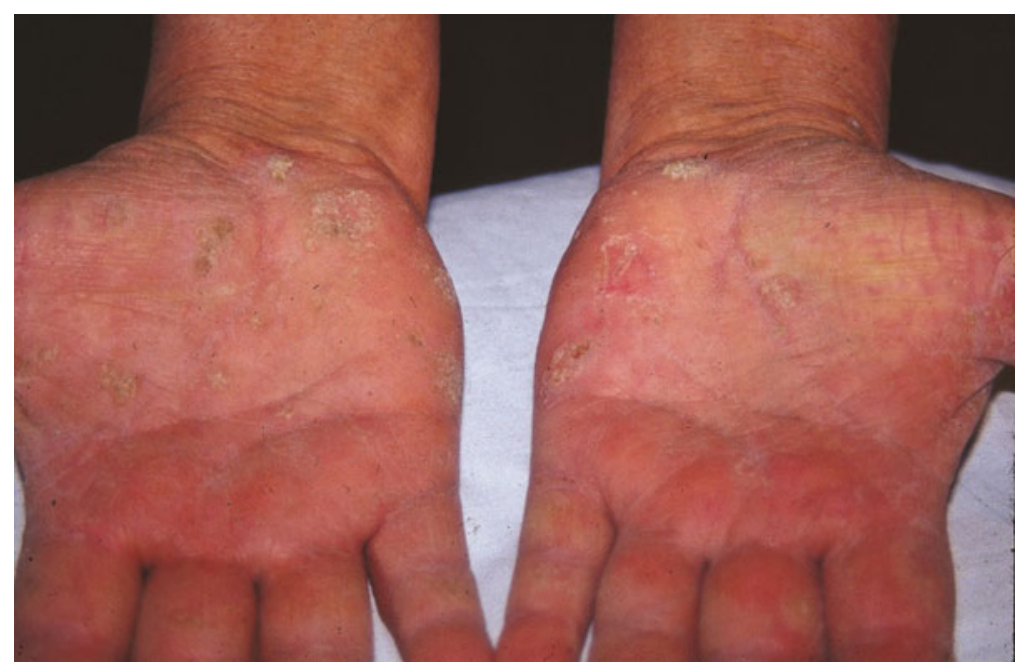

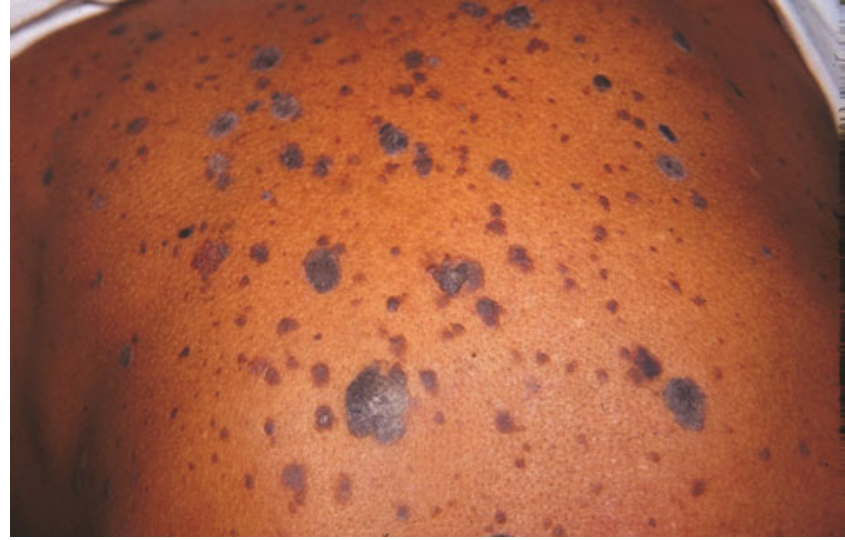

Fig. 25.2 Hyperpigmentation and hyperkeratosis lesions of the back induced by chronic exposure to arsenic from consumption of contaminated drinking water

Epidemiological studies have confirmed the role of arsenic in the induction of cancers of the skin. Of the metals known to exhibit dermal toxicity, only arsenic has been shown conclusively to be carcinogenic (Chen et al. 1992). Squamous cell carcinomas in situ (Bowen's disease) and basal cell carcinomas of the skin have been associated with chronic inorganic arsenic ingestion with a latency period of 2-20 years after exposure (Maloney 1996; Tsai et al. 1999). In addition, epidemiological studies have provided suggestive evidence linking arsenic exposure to various internal cancers, including angiosarcoma of the liver, lung cancer, and bladder cancer. In the majority of these cases, in which the internal cancer is ascribed to arsenic exposure, some dermatologic hallmark of arsenic poisoning (such as hyperor hypopigmentation) is identified.

Arsenical keratosis is a well-established clinical entity resulting from chronic exposure. The lesions are usually most pronounced on the palms and soles, although they can occur on the trunk and other areas of the extremities (see
Fig. 25.1). Arsenical keratoses are characterized by several specific pathologic features, including hyperkeratosis, parakeratosis, and acanthosis (see Fig. 25.2). Nuclear atypia is sometimes present as well. In severe atypia, squamous cells exhibit hyperchromatic nuclei and a disorderly arrangement within the epithelium. Within the spectrum of keratotic lesions, arsenical keratosis may be differentiated from the more commonly diagnosed actinic keratosis by the absence of epidermal atrophy and basophilic degeneration of the upper dermis. All arsenical skin changes, including keratoses, tend to occur in non-exposed sites with an absence of dermal solar elastosis noted histologically.

As a human carcinogen, inorganic arsenic remains an enigma because arsenic-related tumors occur in humans but not in laboratory animals. The biological mechanisms by which arsenic induces chronic effects including cancer are not well understood and are the subject of considerable research efforts. Arsenic does not directly damage DNA but rather causes chromosome aberrations, aneuploidy, cell transformation, and gene amplification in many cell types. Recently, arsenic-induced carcinogenesis has been studied using molecular biological methods. Among the oncogenes evaluated, the tumor-suppressor gene $p 53$ appears to play a role in arsenic-induced carcinogenesis. In one study from an endemic area, 48 cases representing a variety of arsenicinduced skin cancers (including Bowen's disease, squamous cell carcinoma, and basal cell carcinoma) were examined (Chung et al. 1998). All of the specimens demonstrated positive $p 53$ immunostaining. Positive $p 53$ staining was identified in all perilesional normal skin as well, which suggested that the p53 mutation may be an early event in arsenic-related carcinogenesis. Another study demonstrated that $p 53$ mutation rates, sites, and types in arsenic-related skin cancer are significantly different from those in ultraviolet-induced cancer, which implicates arsenic as the etiologic agent and suggests a possible mechanism of action (Hsu et al. 1999). 
In the absence of animal models, in vitro studies become particularly important in providing information on the carcinogenic mechanisms of arsenic toxicity. Arsenic and arsenical compounds have been reported to induce morphological changes in cultured cells. Experimental studies have indicated that arsenic is cytotoxic and able to transcriptionally activate a significant number of stress genes in transformed human liver cells (Tchounwou et al. 2000, 2001). Arsenic and arseniccontaining compounds have also been shown to be potent clastogens both in vivo and in vitro. Arsenical compounds have been reported to induce sister chromatid exchanges and chromosome aberrations in both human and rodent cells in culture (Nakamuro and Sayato 1981; Barrett et al. 1989). Arsenical compounds have also been shown to induce gene amplification, arrest cells in mitosis, inhibit DNA repair, and induce expression of the $c$-fos gene and the oxidative stress protein heme oxygenase in mammalian cells (Ramirez et al. 1997; Jingbo et al. 2002), and they have been implicated as promoters and comutagens for a variety of agents (Cavigelli et al. 1996).

Research has also indicated that inorganic arsenic does not act through classic genotoxic and mutagenic mechanisms but may be a tumor promoter that modi-fies signal transduction pathways involved in cell growth and proliferation (Simeonova and Luster 2000; Kitchin 2001). Modulation of gene expression and/or DNA-binding activities of several key transcription factors, including nuclear factor kappa $B(\mathrm{NF \kappa B})$, tumor-suppressor protein (p53), and activating protein-1 (AP-1) has been associated with arsenic exposure (Barchowsky et al. 1996). Mechanisms of AP-1 activation by trivalent arsenic include stimulation of the mitogen-activated protein kinase (MAPK) cascade with a consequent increase in the expression and/or phosphorylation of the two major AP-1 constituents, c-jun and c-fos (Simeonova and Luster 2000).

Much remains to be learned about arsenic and its toxicity to skin, and similar challenges remain when examining arsenic and its toxicity to other important organ systems in the body. As is discussed in the next section, arsenic damage to the nervous system is relatively acute, and the extent of damage is proportional to the exposure dose (see also Chaps. 12 and 22 , this volume).

\subsection{The Brain}

\subsubsection{Introduction}

It should be recognized that a number of metallic elements, such as iron, copper, and manganese, are essential to life and play an important role in the functioning of the central nervous system (CNS); nevertheless, that certain metals, such as lead and mercury, have neurotoxic properties has been acknowledged since ancient times. The brain must be viewed in a somewhat different light than other organ systems because of its position behind the protective shield of the blood-brain barrier. Because of this critical protective barrier, one must recognize that, for a metal to induce neurologic damage, it must be able to cross the blood-brain barrier, enter the CNS, and gain access to target cells in sufficient quantity to produce pathologic damage. Compounds in which the metal is linked to a lipophilic organic compound tend to be particularly neurotoxic as they can readily cross the lipid membranes that comprise the blood-brain barrier. One example is mercury, which, in its inorganic form, is relatively nontoxic to the CNS; however, when mercury is methylated to form methylmercury, the compound rapidly crosses the blood-brain barrier, is readily taken up by neurons, and produces massive cellular destruction. This results in the severe parenchymal damage that occurred in the outbreak of severe CNS damage in Minamata, Japan (see discussion below). Finally, it should be recognized that the effects of toxins that damage neurons are particularly serious because of the inability of these cells to regenerate.

Certain metals function as classic toxins to the nervous system, in which damage is relatively acute following exposure, and the extent of damage is proportional to the exposure dose. One such example is arsenic. As noted earlier, arsenic is generally found as an impurity of ores containing copper, lead, gold, and zinc. Exposure to arsenic is a relatively rare event but does occur due to accidental ingestion, suicide, or murder and most commonly is related to occupational activities and consumption of contaminated drinking water (see Chap. 12, this volume). Arsenic is an active ingredient of herbicides, insecticides, and other pesticides. In cases of acute arsenic poisoning, sudden fatal circulatory collapse may follow ingestion of a single large dose. When smaller doses are involved, gastrointestinal symptoms will predominate initially to be followed after a period of $2-3$ weeks by the development of a rapidly progressive peripheral neuropathy. The extent and severity of the neurologic symptomatology will depend on the arsenic dosage. In cases of chronic exposure to lower doses of arsenic, a sensory neuropathy is generally observed. Relatively little is known of the mechanism by which arsenic produces its toxic damage, but recent studies suggest that the process involves primary axonal damage.

\subsubsection{Lead Poisoning: Acute and Chronic Effects}

Lead is perhaps the most important metallic neurotoxin. Adults are relatively resistant to its effects, and only in high doses is a peripheral neuropathy encountered. In children, however, the effects of relatively low doses can be much 
more devastating. High doses in children can cause acute lead encephalopathy, a life-threatening condition characterized by generalized cerebral edema with increased intracranial pressure, which leads to transtentorial and cerebellar tonsillar herniation. Clinical features of acute lead encephalopathy may include ataxia, seizures, stupor, coma, and often death. Almost always other associated systemic signs of lead exposure, such as anemia and the presence of lead lines on x-rays of the long bones, are noted in affected children. At autopsy, the brain is markedly swollen with compressed gyri, obliterated sulci, and collapsed lateral ventricles. Uncal and cerebellar tonsillar herniation are commonly encountered. Microscopically, there is a breakdown of the blood-brain barrier with transudation of fluid into the pericapillary space and ischemic damage to cerebral cortical neurons. Once again, the adult is apparently resistant to such toxic changes, and it is extremely rare to see acute encephalopathy in an adult even following extremely high-exposure doses. More typically, adults exposed to lead develop a peripheral neuropathy with wrist drop and/or ankle drop. Exposure in children leading to encephalopathy is primarily through the eating of peeling paint chips in houses dating from an era when leadbased paints were employed. In general, exposure to lead can come from the air, in the form of lead fumes (e.g., firing range operators, stained glass workers, solderers); from water contaminated by lead plumbing components (particularly in acid conditions); the use of lead-containing vessels (lead crystal, lead glazes of pottery in which acid liquids have been stored); and airborne particulates, such as is found in restorers of old homes and bridge workers. Other workers who are particularly prone to high lead exposures are battery production workers and bronze workers.

Largely through the work of Needleman and colleagues (1979; 1988; 1990), the long-term effects of lower doses of lead exposure on children have been increasingly recognized. This relates to the adverse effects of lead on intellectual functioning as well as its association with behavioral problems in children exposed to what had been previously considered to be relatively low lead burdens. Documenting low-level, chronic lead exposure has not been easy to accomplish. It is clear that determining a single blood lead level in a child can be completely misleading. In the initial studies of Needleman et al., lead exposure was estimated through the calculation of lead levels in the dentine of deciduous teeth. These studies suggested that exposure to relatively low levels of lead in childhood is associated with a slight, but significant, drop in IQ. Furthermore, such low-level exposures have been associated with a tendency toward disturbed classroom behavior. Follow-up studies on children with elevated lead levels showed a markedly high dropout level from high school, increased absenteeism, and impaired eye-hand coordination. The neuropathologic substrate of all such effects of low-level, chronic lead exposure remains unclear, but these data have resulted in a progressive lowering of what is considered an "acceptable" blood lead level.

\subsubsection{Mercury Poisoning: Inorganic Versus Organic Forms}

The hazards of inorganic mercury poisoning have been known since Roman days, and the dangers of working in the mercury mines of Almedon, Spain, have been widely acknowledged for centuries. Central nervous system symptoms related to such exposure are generally related to the presence of high concentrations of inorganic mercury fumes. These produce tremor and irritability which typically are reversible upon removal from the exposure source. The behavioral disturbances that result gave rise to the notion of being "mad as a hatter," a saying that refers to the practice of employing mercury rather indiscriminately in the felt tanning industry of Victorian England and the subsequent frequency of cases of inorganic mercury poisoning among hatters. Nevertheless, oral mercury-containing calomel medicinals have been used relatively safely over the centuries, and inorganic mercury has a relatively low level of toxicity. On the other hand, exposure to organic mercury, such as methylmercury, causes dramatic nervous system destruction (Hunter and Russell 1954).

The importance of this distinction was dramatically demonstrated in the tragic outbreak of methylmercury poisoning among Japanese villagers living along Minamata Bay (Marsh 1979). In the small town of Minamata, Japan, on the southern portion of the island of Kyushu, a large chemical factory employed a significant amount of inorganic mercury as a catalyst for the production of the raw ingredients of plastic. Some of this mercury was discharged into Minamata Bay. The mercury deposited in the sediment of the bay was subsequently taken up by certain bacteria, which are capable of methylating it to form methylmercury (Jensen and Jernelov 1969). These bacteria entered the food chain to eventually deposit methylmercury in the fish, the major protein source of the local villagers.

The methylated form of mercury readily crosses the blood-brain barrier, inducing severe neuronal destruction in extremely small doses. Indeed, the solubility and neurotoxicity of methylmercury are so great that fatal poisoning has been reported in a research chemist who was exposed to minute amounts of dimethylmercury that gained access to his skin directly through his latex gloves. Clinically, exposed patients initially show a constricted visual field, paresthesias, gait ataxia, and impairment of vibration sense (stereognosis) and two-point discrimination. Subsequently, more profound visual loss (frequently progressing to total blindness), ataxia, and sensory-motor signs are noted. The neuropathologic 
lesions of methylmercury poisoning are quite distinct, with acute necrosis of the calcarine and pre-central cortex and the cerebellum (Shiraki 1979). Nerve cell loss is severe, with a profound glial response. In the cerebellum, the neuronal loss predominates in the internal granular layer, with sparing of the Purkinje cells. Although blindness is a common complication of the disease, the retina appears to be intact, and the loss of vision is thought to be directly related to destruction of the primary visual (calcarine) cortex. In patients with prolonged survival after exposure to methylmercury, dramatic atrophy and glial scarring of the abovementioned regions are observed. Among the most severely affected victims of the Minamata outbreak were newborns who were exposed in utero. The methylmercury readily crossed the placenta and produced dramatic widespread nervous system destruction.

\subsubsection{Tin Poisoning: An Example of Selective Toxicity of Organic Metal Complexes}

A phenomenon similar to that of enhanced neurotoxicity of methylmercury also occurs following exposure to tincontaining compounds. Metallic tin and its inorganic salts have been included in medicinal preparations since the sixteenth century. These were widely administered in relatively high doses without any apparent adverse health effects; however, organic tin compounds, similar to organic mercury compounds, are highly lipid soluble and are also highly toxic to the nervous system (Cavanagh and Nolan 1994). Unfortunately, these characteristics were learned following a serious outbreak of organic tin poisoning in 1954 in France due to the introduction of the drug Stalinon for the treatment of staphylococcal infections. Each Stalinon capsule contained $15 \mathrm{mg}$ of diiodide-diethyltin. Of those exposed to this drug, approximately half died, one-third recovered, and the remainder suffered from a wide variety of chronic neurologic deficits. Autopsies on the acute fatal cases showed evidence of an unusual form of diffuse edema that was confined to the white matter. Subsequent experimental work has shown that triethyltin produces a characteristic and selective white matter edema, presumably through its toxic effects on the functioning of oligodendroglial membranes. Interestingly, animals exposed to trimethyl tin fail to show evidence of white matter edema but instead develop a selective necrosis of neurons of the hippocampus. The mechanism behind this dramatic difference in the selective toxicity of these two extremely similar compounds remains unclear; nevertheless, the organic moiety on each form allows for its rapid uptake into the CNS, thus providing access to the different cellular targets for its toxicity.

\subsubsection{Manganese-Induced Parkinsonism}

Manganese is a neurotoxic metal that is capable of readily entering the CNS when it reaches the general circulation. Upon reaching the brain, manganese accumulates selectively in the globus pallidus, where it can destroy local nerve cells. Manganese is the twelfth most abundant element in the Earth's crust and the fourth most widely used metal in the world. Eight million tons of manganese metal are extracted annually, of which $94 \%$ is employed in the manufacture of steel. Manganese is also used in the manufacture of batteries. Potassium permanganate is a widely employed bactericidal and fungicidal agent in water purification processes. Additionally, methylcyclopentadienyl manganese tricarbonyl (MMT) is an organic manganese compound that has been used as anti-knock additive to gasoline. Medically significant manganese toxicity is almost exclusively encountered in an industrial setting, either in association with manganese mining or in smelting operations. The classic papers of Mena and coworkers (Mena et al. 1967; Mena 1979) documented the development of psychiatric and parkinsonian features in a group of manganese miners in Chile, and more recent papers from Taiwan have documented cases seen in association with smelting (Olanow et al. 1994).

The clinical features of manganese neurotoxicity closely resemble Parkinson's disease but have more prominentdystonic features. Initial stages typically include psychiatric disturbances, such as behavioral abnormalities, hallucinations, and, at times, frank psychosis. This syndrome is referred to as "manganese madness" or locura manganica. Not all cases pass through the psychiatric phase of the disease and present with the extrapyramidal manifestations. The extrapyramidal features consist of bradykinesia, gait disturbance, postural instability, rigidity, micrographia, masked facies, and speech disturbances. Although tremors may be seen, they usually are not the "pill-rolling" tremors seen at rest that are typical of Parkinson's disease but are described as more of an intension tremor. Dystonic features can be rather prominent with facial grimacing and plantar flexion of the foot, which results in a very characteristic gait disturbance. The gait of manganese poisoning consists of the patient keeping the foot dorsoflexed and walking with elbows flexed and spine erect. This rather unique and characteristic gait is commonly referred to as coq au pied or "cock walk," as it resembles the strutting of a rooster.

The manganese that produces this form of neurotoxicity is generally thought to enter the body through the lungs. Experimental studies have shown that airborne manganese is readily taken up into the systemic circulation and is selectively deposited in the globus pallidus of the brain, where the major site of damage occurs (Newland et al. 1989; Olanow et al. 1996). Pathological studies of both 
experimental models and human cases demonstrate evidence of selective neuronal loss and gliosis in globus pallidus (primarily the medial segment) and striatum. Accompanying the neuronal loss is a dramatic increase in the amount of stainable iron within the damaged regions (Olanow et al. 1996). Whether the increased iron participates in the neuronal damage through oxidative damage or is secondary to the parenchymal destruction remains unclear. The substantia nigra pars compacta is the location of the dopaminergic cells that project to the striatum and are the main targets of damage in Parkinson's disease, but they remain intact in manganese poisoning. Lewy bodies, the characteristic microscopic feature of Parkinson's disease, are not encountered in cases of manganese-induced parkinsonism. Presumably dysfunction of the extrapyramidal system occurs secondary to damage to the globus pallidus and striatum, the major targets of the striatonigral projections. Because the postsynaptic targets of dopaminergic transmission are largely lost, treatment by levodopa is generally considered to be ineffective in manganese-induced parkinsonism. This represents a major defining characteristic that distinguishes manganese-induced parkinsonism from Parkinson's disease.

\subsubsection{Metals and Age-Related Neurodegenerative Diseases}

The accumulation of metals in the brain has also been associated with several of the age-related neurodegenerative disorders. The two metals most often cited are aluminum and iron. Excess amounts of both metals have been identified in microprobe studies within the characteristic neurofibrillary tangles of cases of Alzheimer's disease (Perl and Brody 1980; Good et al. 1992a). Similarly, increased concentrations of iron and aluminum have been noted in the neurons of the substantia nigra in cases of Parkinson's disease (Good et al. 1992b). It is not considered likely that such elemental accumulations play an etiologic role in these diseases, although they may certainly have the capacity to contribute to their pathogenesis (Perl and Good 1992). Iron, through its ability to donate electrons in energy transfer reactions, may actively support oxidative damage. Evidence for oxidative damage in the brains of Alzheimer's disease and Parkinson's disease victims is well established (Markesbery 1997). Aluminum is a highly charged element that binds strongly to proteins and acts as a cross-linking stabilizer. Many of the proteins comprising the intraneuronal inclusions that characterize the neurodegenerative diseases (the neurofibrillary tangle being the most prominent example) are highly cross-linked and thus resistant to degradation. Whether aluminum serves this role in the natural history of the disorder remains unclear, although recent evidence appears to support this concept. These findings have raised concerns regarding the source of such elemental accumulations and whether aspects of environmental and geological exposures might play a role in the further onset of these age-related disorders. These questions remain largely unresolved.

One question that is resolved is the critical role oxygen plays in maintaining the tissues in the brain. Effects of metals on the lungs can secondarily affect respiratory effectiveness, which will have secondary effects on the brain. Toxicity of metals and the lung are reviewed in the next section.

\subsection{Inhalation Injury}

\subsubsection{Introduction}

Zenker (1867) first proposed the term "pneumonokoniosis" as a name for lung disease resulting from the inhalation of dust. While many forms of pneumoconioses are known today, each with its own etiologic agent, the definition of pneumoconiosis varies. Some authors restrict the term to non-neoplastic reactions of the lung to inhaled minerals or organic dusts, excluding asthma, bronchitis, and emphysema. Others use the term more broadly to define the accumulation of abnormal amounts of dust and the resulting pathologic reactions (Gibbs 1996). These reactions range from minimal responses to inert dust particles, such as interstitial dust macules, to lethal scarring associated with fibrogenic dusts (see also Chaps. 10 and 19, this volume). Damage caused by inhaled particles depends on a variety of factors, including the number, size, and physiochemical properties of the particles; the deposition, clearance, and retention of particles in the respiratory tract; the host's inflammatory response to the inhaled particles; and the duration of exposure and interval since initial exposure, as well as interactions with other inhaled particles, particularly cigarette smoke (Roggli and Shelburne 1994).

\subsubsection{Deposition, Clearance, and Retention}

The respiratory system acts like a filter by removing particles and bacteria from inhaled air and leaving exhaled air essentially free of contaminants (Brain and Valberg 1979). With each breath, air is drawn through the nares into the nasopharynx and trachea and on into the conducting system of the lungs. Air then passes by way of the bronchi, terminal bronchioles, respiratory bronchioles, and alveolar ducts to the alveoli. In healthy individuals, the tracheobronchial tree is covered by a thin, watery layer of mucus, which is continuously moved up and out of the lungs by ciliated bronchial epithelium. The velocity of inspired air decreases 
over the course of the airways. Flow rates decrease slightly in the trachea and are markedly reduced in the third through fifth generations of bronchi. At the level of the terminal bronchiole, flow rates are not more than $2-3 \mathrm{~cm}$ per second (Morgan and Seaton 1975).

Particles that are nearly spherical in shape are called compact particles, whereas those with a length-to-width ratio of 3:1 or greater are called fibers. Compact particles with an aerodynamic equivalent diameter of $1-5 \mu \mathrm{m}$ are the most likely to deposit in the lung parenchyma (Roggli and Shelburne 1994; Gibbs 1996), whereas particles with extreme shapes, such as fibers and plates, tend to deposit in the airway walls (Gibbs 1996). Fiber deposition is primarily a function of diameter and less a function of length (Gibbs 1996). Fibers with diameters below $3 \mu \mathrm{m}$, even when several hundred micrometers in length, can align axially with the airstream (Timbrell et al. 1970) and can deposit in the alveoli; however, the longer the fiber, the less its statistical chance of reaching the alveolus (Churg 1998a).

Deposition refers to the fraction of particles in inspired air that are trapped in the lung and fail to exit with expired air. Deposition of particles occurs in the respiratory tract as a consequence of the physical processes of inertial impaction, sedimentation, and diffusion. Inertial impaction occurs when the air current carrying a particle changes direction and the momentum of the particle carries it along its original path. This frequently results in particle deposition at bifurcation points in the respiratory tract (Brain and Valberg 1979). Sedimentation of particles occurs secondary to the force of gravity, whereas very small particles are deposited by diffusion and Brownian motion. In general, a high percentage of particles greater than $1 \mu \mathrm{m}$ in diameter is filtered in the nasopharynx by inertial impaction and sedimentation. A smaller percentage of particles is deposited by the same mechanisms in the trachea and bronchi. When particles are under $0.5 \mu \mathrm{m}$ in diameter, they deposit in the alveoli by sedimentation and diffusion (Morgan and Seaton 1975). Breathing rate, tidal volume, and nose versus mouth breathing influence the pattern of deposition (Roggli and Shelburne 1994; Gibbs 1996).

Clearance is the output of particles previously deposited in the respiratory tract. Mechanisms such as dissolution and absorption, coughing, sneezing, and tracheobronchial and alveolar transport systems keep the lungs relatively free of foreign material (Brain and Valberg 1979). The tracheobronchial system, also known as the mucociliary escalator, extends from the terminal bronchiole to the glottis. Particles deposited in the conducting system adhere to a thin layer of mucus secreted by the mucous glands and goblet cells of the bronchial tree; subsequently, particles are swept toward the glottis by ciliary action and are swallowed or expectorated. The rate of transport is approximately $3 \mathrm{~mm}$ per minute, with $80-90 \%$ of particles removed within 2 h. The bronchial mucus is arranged in two layers: an outer viscous gel, which does not absorb water, and an inner liquid solid phase in which the cilia beat. The function and integrity of the inner layer are affected by dehydration. Ciliary function is influenced by ionic charges, the presence of oxidants, high concentrations of oxygen, low concentrations of adenosine triphosphate, and the presence of oxidants and cigarette smoke. In the alveolar transport system, particles are dissolved, removed to lymphatics, engulfed by macrophages, or transported by surface fluid movement to the mucociliary escalator (Morgan and Seaton 1975). Retention is defined as the amount of particulate matter found in the lungs at any time and is dependent on the rates of deposition and clearance.

The diseased and blackened lungs of miners who die of coal worker's pneumoconiosis contain less than $2 \%$ of the dust originally deposited in the lungs (Brain and Valberg 1979). This illustrates the efficiency of the respiratory tract as a filter; however, the normal defense mechanisms of the lung can be overwhelmed by high exposure levels to inhaled foreign material, which increases the probability of a pathologic response.

\subsubsection{Pathologic Responses to Inhaled Particles}

Inhaled particles can produce a variety of injury patterns in the lung, which include diffuse alveolar damage (fume exposure), dust macules with or without small airway fibrosis, diffuse interstitial fibrosis, alveolar proteinosis, granulomatous interstitial pneumonitis, giant-cell and desquamative interstitial pneumonitis, and lung cancer. Generally, these injury patterns lack specific features that implicate a causative agent.

Diffuse alveolar damage (DAD), the histologic correlate to adult respiratory distress syndrome (ARDS), is the most common serious reaction to inhaled gases and fumes (Wright and Churg 1998). Microscopically, DAD is characterized by hyaline membranes lining edematous alveolar septa. Virtually any noxious gas or fume (e.g., beryllium and cobalt metal) inhaled in sufficient concentration can potentially cause DAD (Wright and Churg 1998); however, numerous other agents, including infectious organisms, drugs, ingestants, shock, and sepsis, cause DAD that is microscopically indistinguishable from that produced by gases and fumes.

Dust macules are nonpalpable, peribronchiolar interstitial aggregates of pigmented dust and dust-laden macrophages. Initially, macules may have little associated fibrosis; however, with sufficient exposure, peribronchiolar fibrosis may occur. This pattern of injury generally has little functional deficit, but due to the radiodensity of the dust it is usually 
associated with an abnormal chest radiograph (Churg and Colby 1998). Agents that produce dust macules include antimony, barium, chromium ore, iron, rare earths, tin, titanium, and tungsten.

A diffuse interstitial fibrosis pattern of injury, an uncommon complication of metal exposure, can be seen with iron (mild fibrosis), aluminum, hard metal (containing cobalt), copper, rare earths, and silicon carbide exposure. Asbestos and mixed dusts containing silicates can also produce interstitial fibrosis.

Alveolar proteinosis pattern is characterized by a relatively uniform filling of alveoli with granular, eosinophilic exudate containing dense bodies and acicular clefts accompanied by a variable amount of chronic interstitial inflammation and fibrosis. This pattern of injury is usually associated with acute exposure to high levels of silica dust and rarely to aluminum dusts.

Giant-cell (GIP) and desquamative interstitial pneumonitis (DIP) patterns of injury can result from exposure to "hard metals." Patchy interstitial fibrosis with mild chronic inflammatory cell infiltrates, accompanied by striking intraalveolar accumulations of macrophages, characterize these two injury patterns. The presence of enlarged, multinucleated alveolar macrophages, which may contain engulfed inflammatory cells, distinguishes GIP from DIP. GIP is characterized microscopically by interstitial fibrosis accompanied by noncaseating granulomas. This pattern can be seen in chronic beryllium disease.

Asbestos (particularly when associated with asbestosis), arsenic, beryllium, cadmium, chloromethyl ether, hexavalent chromium compounds, nickel, and radon have been linked to lung cancer. Lung cancer occurring in occupationally exposed individuals is histologically indistinguishable from cancer in unexposed individuals (see also Chap. 19, this volume).

Although many forms of pneumoconioses are known, only a handful are seen by the surgical pathologist with any regularity (Table 25.1). The ensuing discussion centers on asbestos and asbestos-related disease, which is considered by many to be the prototype inhalation injury.

\subsubsection{Asbestos}

Asbestos is a group of naturally occurring mineral fibers with the economically useful properties of flexibility, high tensile strength, acoustic insulation, and corrosion, thermal, and electrical resistance. These properties led to the widespread incorporation of asbestos into many products including fireproofing and insulating materials, cloth, cement, plastics, floor tiles, paper, paints, and brake, clutch, furnace, and kiln linings. Virtually everyone in the general population is

\section{Table 25.1}

\begin{tabular}{l}
\hline Asbestos-related disease \\
\hline Benign diseases \\
\hline Pleural plaques \\
\hline Diffuse pleural fibrosis \\
\hline Benign asbestos effusion \\
\hline Rounded atelectasis \\
\hline Asbestosis \\
\hline Malignancies \\
\hline Lung cancer \\
\hline Malignant mesothelioma
\end{tabular}

exposed to a low level of asbestos fibers, and normal lungs can contain small numbers of them (Gibbs 1996).

Asbestos fibers occur as hydrated fibrous silicates that are mined directly from the Earth. The world's principal, commercially exploited mines are found in Canada, South Africa, Western Australia, and Russia (Roggli 1994). Based on physical and chemical features, asbestos is classified into two major mineralogic groups: serpentine fibers (containing only chrysotile) and amphiboles, comprised of crocidolite, amosite, tremolite, anthophyllite, and actinolite. Serpentine fibers are curly and pliable, whereas the amphiboles are straight, rigid, and brittle (see also Chap. 19 , this volume).

Until the late 1970s, chrysotile (white asbestos) accounted for $95 \%$ of the asbestos used commercially (Becklake 1983), while crocidolite (blue asbestos) and amosite (brown asbestos) made up the remaining 5\%. Current usage is almost $100 \%$ chrysotile asbestos. Tremolite, anthophyllite, and actinolite are encountered most commonly as contaminants of other minerals, including chrysotile ore and probably most forms of processed chrysotile products (Dupres et al. 1984). These forms of amphibole asbestos have seen little commercial use, in part because of their physical and chemical properties but primarily due to the lack of commercially useful deposits (Churg 1998a).

It is generally accepted that exposure to the amphiboles is far more pathogenic than exposure to chrysotile, due to the differential rate of fiber clearance between these groups (Gibbs 1996). Evidence indicates that amphibole fibers longer than $20 \mu \mathrm{m}$ cannot be cleared from the peripheral lung (Morgan 1980). The straight, broad amphibole forms do not readily fragment, whereas the long fibers of chrysotile fragment into short, straight fibers that are cleared (Churg 1998a). Moreover, chrysotile is thought to be chemically unstable and likely to dissolve, whereas amphibole fibers are stable in the environment of the lung (Hume and Roe 1992). Zielhuis (1977) broadly classified exposure to asbestos into direct, indirect (bystander), paraoccupational (women washing contaminated work clothes), neighborhood 


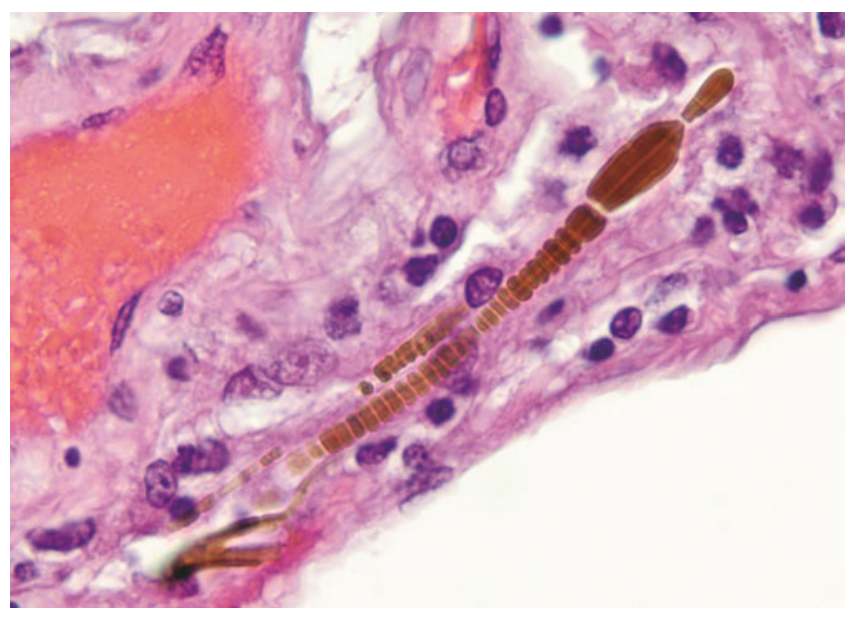

Fig. 25.3 Asbestos body (oil-immersion photomicrograph, $\times 400$ ) with the characteristic clear core that is surrounded by an iron and mucopolysaccharide coating with terminal bulbs

(living in the vicinity of asbestos mines or factories), and ambient (atmospheric contamination).

Asbestos bodies are the most characteristic feature of asbestos exposure (see Fig. 25.3). These structures are composed of a clear asbestos core surrounded by a golden yellow coating of iron and mucopolysaccharides. The clear core distinguishes asbestos bodies from other ferruginous bodies. The coat may be continuous or bead-like with terminal bulbs. Fiber dimensions are important factors in determining whether a fiber becomes coated (Roggli 1992). Longer thicker fibers are more likely to become coated than shorter thinner ones (Morgan and Holmes 1985), and fibers less than $20 \mu \mathrm{m}$ in length rarely become coated (Morgan and Holmes 1980). Because alveolar macrophages are unable to phagocytize long fibers completely within their cell cytoplasm, they coat the asbestos fibers with an iron-protein matrix (Roggli 1994). For many years, asbestos bodies were thought to be markers of asbestos exposure only in primary asbestos workers. Subsequent studies indicate that asbestos bodies are present in virtually everyone in the general population. Of the asbestos bodies identified in these studies, 98\% contained amphibole cores, while the cores in the remaining $2 \%$ were chrysotile asbestos (Churg and Warnock 1981); however, asbestos bodies are present in such small numbers from background exposure that an observer should not see an asbestos body in more than 1 in 100 iron-stained, routinesized paraffin sections (Roggli and Pratt 1983).

\subsubsection{Asbestos-Related Diseases}

A variety of benign and malignant diseases of the pleura and lung are associated with asbestos exposure. The benign diseases consist of pleural plaques, diffuse pleural fibrosis, pleural effusion, rounded atelectasis, and asbestosis. Carcinoma of the lung in the presence of asbestosis and malignant mesothelioma of the pleura comprise the malignant diseases. Although asbestos fibers are present in virtually everyone in the general population, disease always occurs with fiber burdens greater than those seen in the general population (Wagner et al. 1988). The various asbestos-related diseases occur at different fiber burdens; in general, the fiber burden required to induce disease is greater for chrysotile, with its tremolite contaminant, than for amosite and crocidolite (Churg 1998b; Churg et al. 1993).

\subsubsection{Benign Pleuropulmonary Disease}

Pleural plaques, the most common form of benign asbestosrelated pleuropulmonary disease, are discrete, raised, irregular foci of dense fibrous tissue. Thin plaques are grayish-white and smooth, whereas thicker ones are pearly-white with either a smooth or bosselated surface. They vary in size from a few millimeters to $10 \mathrm{~cm}$ across, and they vary in consistency from leathery to heavily calcified and brittle (Roberts 1971). Pleural plaques occur most frequently on the posterolateral parietal pleura and on the domes of the hemidiaphragms. Generally, the apices, anterior chest wall, and costophrenic angles are not involved. Pleural plaques are seen predominantly in persons exposed to asbestos, and bilateral plaques are almost pathognomonic of asbestos exposure (Roggli 1994). There is evidence of a dose-response relationship between the presence of pleural plaques and the number of asbestos bodies in the lung (Roberts 1971). Microscopically, pleural plaques consist of dense, paucicellular, hyalinized collagen arranged in a basket-weave pattern in which asbestos bodies are not seen.

In contrast to pleural plaques, diffuse pleural fibrosis typically involves the visceral pleura. The lung may be encased in a thick rind of fibrotic pleura that bridges the major fissures and distorts the edges of the lung (Churg 1998b). In its most severe form, fusion of the visceral and parietal pleura obliterates the pleural cavity, which results in a condition known as fibrothorax. Microscopically, the thickened fibrous pleura consists of dense collagenous tissue admixed with varying numbers of chronic inflammatory cells.

Diagnosis of benign asbestos effusion is based on: (1) a history of exposure to asbestos, (2) confirmation of the effusion by radiographs or thoracentesis, (3) absence of another disease that could produce an effusion, and (4) no malignant tumor developing within 3 years after the effusion (Epler et al. 1982). Asbestos-induced pleural effusion is characteristically a serous or serosanguineous exudate with increased numbers of eosinophils. Most effusions are small (usually less than $500 \mathrm{~mL}$ ) and asymptomatic and may persist from 2 weeks to 6 months (Fraser et al. 1999a). In 1982, Epler et al. reported that the prevalence of 
asbestos-induced pleural effusion was dose related and, with a shorter latency period than other asbestos-related disease, it is the most common disorder in the first 20 years after asbestos exposure.

Rounded atelectasis is most often an incidental radiographic finding and is resected for suspicion of neoplasm (Churg 1998b). Radiographically, rounded atelectasis is a unilateral, rounded, pleural-based mass in the lower lobe of the lung, with one or more curvilinear densities radiating from the mass toward the hilum of the lung (Comet's tail sign). Grossly, the visceral pleura is irregularly thickened and invaginated into the underlying lung. Pleural fibrosis and folding, accompanied by a variable degree of parenchymal atelectasis and fibrosis, are seen microscopically. The majority of cases have a history of asbestos exposure; however, other causes of chronic pleuritis, such as congestive heart failure, pulmonary infarct, tuberculosis, and histoplasmosis, have also been associated with rounded atelectasis.

Roggli and Pratt (1992) describe asbestosis as the prototype of disease caused by the inhalation of mineral fibers. Asbestosis is defined as interstitial fibrosis of the lung parenchyma in which asbestos bodies or fibers may be demonstrated, and it is the only asbestos-related disease to which this term should be applied (American Thoracic Society 1986). Asbestosis shows a dose-response relationship, and there appears to be a threshold below which asbestosis is not seen (Browne 1994). The time from initial exposure to the appearance of asbestosis-the latency period-is inversely proportional to the exposure level and is generally several decades (Roggli and Pratt 1992). Studies suggest that cigarette smoke acts synergistically with asbestos by increasing the incidence of asbestosis (Barnhart et al. 1990; Roggli and Pratt 1992).

The clinical, physiologic, radiologic, and pathologic findings in asbestosis vary with the severity of the disease. The clinical and physiologic findings are not pathognomonic of asbestosis, and they can be seen in diffuse interstitial fibrosis of any cause. Patients with well-established disease usually present with shortness of breath, basilar endinspiratory crepitations, and a restrictive defect with decreased diffusing capacity on pulmonary function testing. Small, irregular linear opacities, most prominent in the lower lobes, are seen on plain films (Fraser et al. 1999a).

The earliest microscopic manifestation of asbestosis is fibrosis of the walls of respiratory bronchioles. As the disease progresses, fibrosis involves the walls of terminal bronchioles and alveolar ducts, and ultimately it extends into the adjacent alveolar septae. The minimal histologic criteria for the diagnosis of asbestosis can be defined as the presence of peribronchiolar fibrosis and asbestos bodies, with or without accompanying alveolar fibrosis (Craighead et al. 1982). As peribronchiolar fibrosis occurs with inhalants other than asbestos, it is suggested that, in the absence of alveolar septal fibrosis, the histologic diagnosis of asbestosis be restricted to cases in which the majority of bronchioles are involved (Roggli 1989). The report from the College of American Pathologists suggests that there must be a minimum of two asbestos bodies in areas of fibrosis for the histologic diagnosis of asbestosis (Craighead et al. 1982).

\subsubsection{Malignant Pleuropulmonary Disease}

Numerous epidemiologic studies demonstrate an association between asbestos and an excess risk of lung cancer (McDonald 1980). The clinical features-anatomic distribution within the lung and histologic subtypes of asbestosrelated lung cancer-are identical to carcinoma in nonexposed individuals. The latency period for asbestos-related lung cancer is lengthy; it peaks at 30-35 years (Selikoff et al. 1980). A linear dose-response relationship exists between exposure and the risk of lung cancer at high-exposure levels (McDonald 1980), but at low-exposure levels Browne (1986) suggests that a threshold exists below which the risk of cancer is not increased. This threshold is thought to be in the range of exposure required to produce asbestosis (Churg 1998b). Available data on asbestos workers indicate that the interaction between cigarette smoke and asbestos in increasing the risk of lung cancer is synergistic, or multiplicative, rather than additive (Greenberg and Roggli 1992). Although persons with asbestosis are at excess risk of developing lung cancer (Doll 1993), investigators are uncertain whether this risk is directly related to the asbestos or to the pulmonary fibrosis. Several studies (Sluis-Cremer and Bezuidenhout 1989; Hughes and Weill 1991) demonstrate an increased rate of lung cancer only in the presence of asbestosis, supporting the view that asbestos is carcinogenic because of its fibrogenicity. Churg (1998b) offers the following approach when evaluating cancer in a given case:

If asbestosis is present, then the carcinoma is ascribed to asbestos exposure. If the patient smokes or has a history of smoking, then smoking is considered a contributing factor to causation. In the absence of asbestosis, the cancer should not be ascribed to asbestos exposure; the most common causative agent in this instance is cigarette smoke.

Malignant mesothelioma may be idiopathic, or it may occur secondary to ionizing radiation, chemical carcinogens, chronic inflammation and scarring of the pleura, and erionite exposure (Browne 1994; Churg 1998b); however, it is most strongly associated with asbestos exposure. The latency period for asbestos-related mesothelioma is long, peaking at 30-40 years, and virtually never occurring before 15 years (McDonald and McDonald 1987). Asbestos fiber types differ in ability to produce mesothelioma, with the amphiboles posing greater risk than chrysotile (Browne 1994). Characteristically, mesothelioma grows over the surface of the lung in thick sheets or as nodular masses, which may progress to 
encase the lung in a hard white rind. Mesotheliomas spread by direct extension into adjacent structures or by lymphatic or hematogenous metastases. Peripheral lung cancers may spread in a similar fashion, which makes the distinction from mesothelioma difficult. Generally, the presence of metastatic disease at clinical presentation favors carcinoma. Mesotheliomas are subclassified by microscopic appearance into epithelioid, sarcomatoid, and biphasic patterns. The diagnosis of diffuse malignant mesothelioma can be very difficult, and it must be distinguished from benign reactive pleural lesions as well as primary and metastatic neoplasms of the pleura.

Frequently, disorders of the lung can lead to cardiovascular dysfunction due to added stress from increased vascular pressures. In the next section, toxicity from metals to the heart is discussed.

\subsection{Cardiovascular System}

Deficiencies of trace elements as well as toxic exposures of metals may be involved in physiologic changes in the cardiovascular system. The clinical, pathologic, and epidemiologic data that support or refute an association between metals and three common cardiovascular disorders-dilated cardiomyopathy, atherosclerosis, and systemic hypertension-are discussed in detail in this section.

\subsubsection{Dilated Cardiomyopathy}

\subsubsection{Selenium Deficiency}

Selenium is an essential nutrient in trace quantities. It combines with cysteine as a component of selenoproteins, many of which have antioxidant properties. For example, thioredoxin reductase, iodothyronine deiodinases, and glutathione peroxidases are selenium-dependent enzymes (Rayman 2000). Selenoproteins are believed to be especially important in relation to the immune response and cancer prevention; however, the role of selenium in the maintenance of the cardiovascular system is less clear (Rayman 2000).

It has been suggested that two levels of selenium deficiency are involved in the causation of human disease (Rayman 2000). Rare endemic diseases occur where the soil is extremely low in selenium, specifically parts of China. These diseases include Keshan cardiomyopathy and Kashin-Beck disease, a deforming arthritis (See Chap. 16, this volume.) High-prevalence diseases, such as cancer and heart disease, may have as a risk factor a relatively mild deficiency of selenium, such as has been reported in Europe. The role of mildly low selenium intake in the development of reproductive disease, mood disorders, thyroid function,

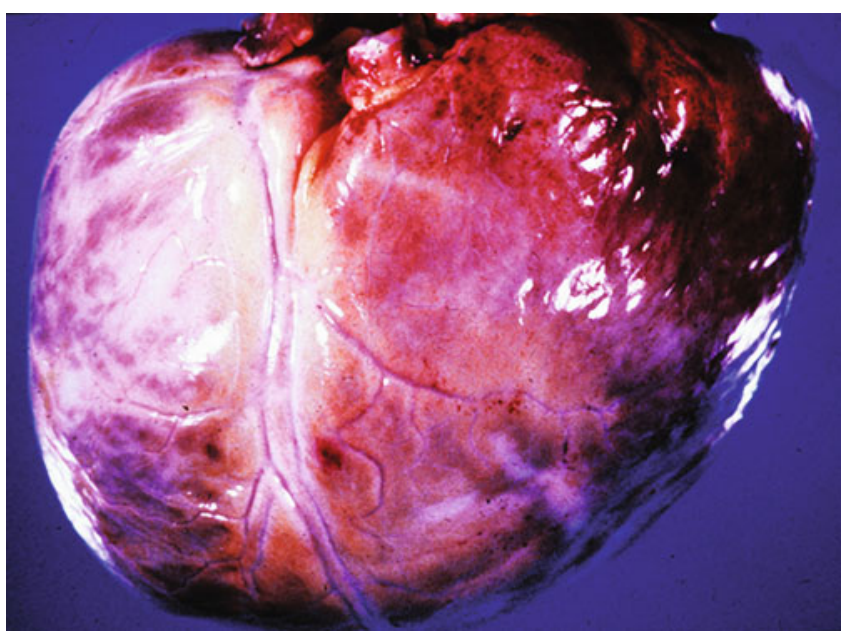

Fig. 25.4 Gross appearance of Keshan cardiomyopathy demonstrating globular configuration of the external aspect of the heart

inflammatory disease, and cancer has been recently reviewed (Rayman 2000).

Markedly inadequate dietary intake of selenium in areas of China with endemic selenium deficiency is associated with a form of dilated cardiomyopathy referred to as Keshan disease (Ge and Yang 1993). It has been demonstrated that selenium levels in soil and rocks vary greatly in China and that areas with low levels have higher rates of the disease (Ge and Yang 1993). Intervention studies that have shown a prophylactic effect of sodium selenite provide further evidence that selenium plays a role in Keshan disease. Morphologically, the condition is characterized by multifocal necrosis and replacement fibrosis of the myocardium, which results in acute or chronic heart failure (Ge et al. 1983) (see Figs. 25.4, 25.5 and 25.6). Some patients with Keshan disease show the clinical features of dilated cardiomyopathy, but autopsy studies from China demonstrate distinct pathologic features that separate Keshan disease from sporadic dilated cardiomyopathy ( $\mathrm{Li}$ et al. 1985). Typical dilated cardiomyopathy does not demonstrate frequent necrosis or fibrosis, which are considered hallmarks of Keshan cardiomyopathy. Ultrastructural observations have shown mitochondrial abnormalities (Ge et al. 1983), which have recently been expanded to include biochemical defects and proteinaceous granular deposits (Yang et al. 1988).

Activities of succinate dehydrogenase, succinic oxidase, and cytochrome $c$ oxidase, $\mathrm{H}(+)$-ATPase and its sensitivity to oligomycin, as well as the response of membrane potential to energization by ATP, are decreased, and affected mitochondria had markedly decreased selenium content (Yang et al. 1988). The sole role of selenium in the causation of Keshan disease is debated, and it is generally believed that other cofactors are responsible for the pathogenesis of Keshan cardiomyopathy, including possible genetic and 
Fig. 25.5 Gross appearance of cross sections of heart muscle demonstrating multiple areas of white tan scar tissue

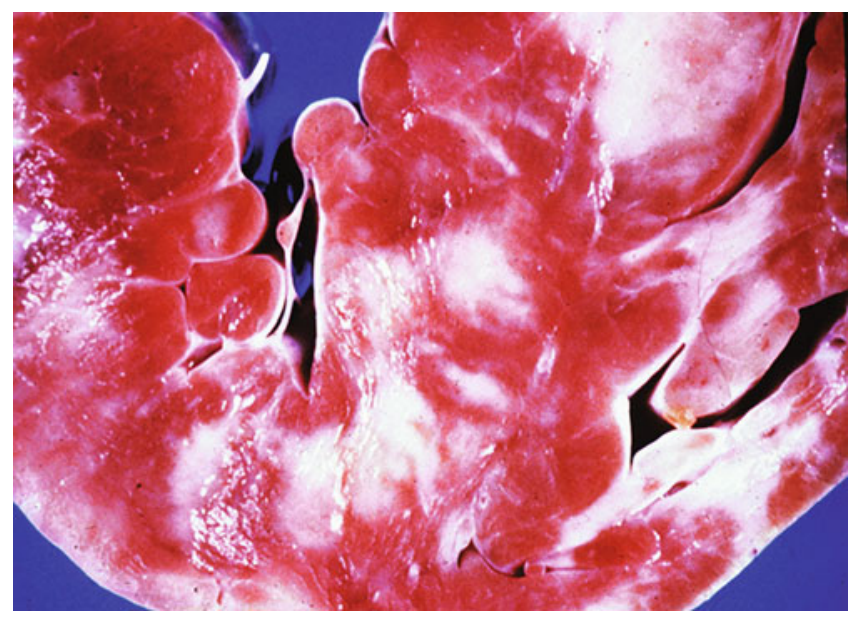

Fig. 25.6 Gross appearance of scar tissue involving the right and left ventricles of the heart

other environmental factors ( $\mathrm{Li}$ et al. 1985). Recently, enteroviral infection as a cofactor has been proposed based on the finding of viral genomes in the myocardial tissue of affected patients (See Chap. 16, this volume).

An association between sporadic dilated cardiomyopathy and selenium deficiency is far less clear than the association between selenium and Keshan disease. Serum levels of selenium may be decreased in patients with dilated and postpartum cardiomyopathy in Chinese and African populations as well as Indians (Vijaya et al. 2000), although the data in idiopathic dilated cardiomyopathy are conflicting in Western and Middle Eastern countries (Raines et al. 1999). There have been anecdotal reports of reversible cardiomyopathy due to selenium deficiency in patients with total parenteral nutrition. Selenium deficiency may play a role in the cardiopathy associated with chronic renal failure, but some studies do not support any association ( $\mathrm{Li}$ and Nan 1989; Chou et al. 1998). The association between dilated cardiomyopathy and dystrophic epidermolysis bullosa does not appear to be mediated by selenium deficiency. The mechanism of cardiomyopathy in selenium deficiency is unclear but is likely related to protection of low-density lipoproteins against oxidative modification, regulation of glutathione peroxidase ( $\mathrm{Li}$ and Nan 1989; Chou et al. 1998), modulation of prostaglandin synthesis and platelet aggregation, and protection against toxic heavy metals (Oster and Prellwitz 1990; Neve 1996).

\section{Cobalt Toxicity}

An epidemic of cardiomyopathy related to cobalt toxicity was reported in 1967 in Canada (Kesteloot et al. 1968). Cobalt ingestion in this epidemic was related to the addition of cobalt sulfate or cobalt chloride to beer as a stabilizer of beer foam. The mechanism of myocyte damage is unclear but may involve increased cardiac vulnerability to oxygen free radicals and may be enhanced in patients with dietary deficiencies. The histologic features of cobalt cardiomyopathy differ somewhat from idiopathic cardiomyopathy, in that greater myofibrillar loss and atrophy and less fibrosis and myocyte hypertrophy are observed in cobalt cardiomyopathy as compared to idiopathic dilated cardiomy-opathy (Centeno et al. 1996) (see Fig. 25.7). Based on heavy metal analysis of cardiac tissues, there is little evidence that elevated cobalt levels are a significant factor in sporadic dilated cardiomyopathy (Centeno et al. 1996).

\section{Mercury-Induced Cardiomyopathy}

Dilated cardiomyopathy has been described in Greenlanders with high mercury levels in their blood, presumably from 


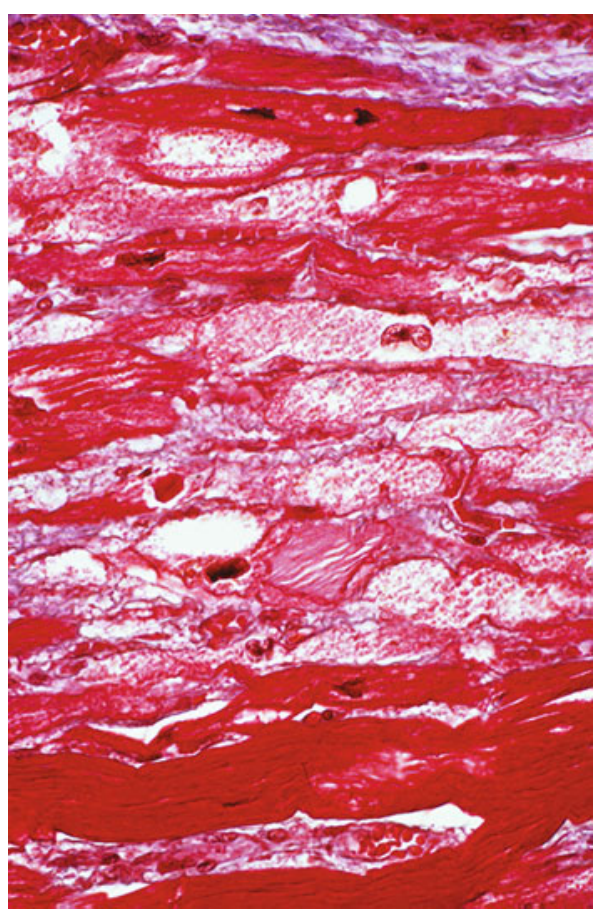

Fig. 25.7 Photomicrograph of myocytes with decreased numbers of myocytes $(\mathrm{H} \& \mathrm{E} \times 400)$

eating seal meat contaminated with high levels of mercury. In addition, evidence suggests that, in cases of sporadic dilated cardiomyopathy, there are thousand-fold elevations of mercury in heart tissue (Frustaci et al. 1999). This latter observation remains to be duplicated, and the mechanism of potential mercury-induced cell damage must yet be elucidated. It is believed that mercury ions may act as calcium antagonists at the actin-myosin junction, inhibiting sarcomere contraction, or that they may disrupt microtubule structure. It has been postulated that a source of mercury in patients with dilated cardiomyopathy may, in addition to occupational exposure, be amalgam fillings, although this remains conjectural.

\section{Iron Overload}

Iron overload may adversely affect the heart in patients with hemosiderosis or primary hemochromatosis. The most common cause of death in patients with hemochromatosis is from cardiac failure and arrhythmias followed by cirrhosis and hepatocellular carcinoma. Histologically, these changes are similar to dilated cardiomyopathy with abundant stainable iron present within myocytes. Most patients with hemochromatosis-related cardiomyopathy have a genetic predisposition to iron overload (primary hemochromatosis); significant cardiac failure in patients with hemosiderosis secondary to blood transfusions is rare. There is little evidence that elevated serum iron plays a role in idiopathic dilated cardiomyopathy, although the data are conflicting
(Oster 1993; Chou et al. 1998). A recently described mutation in the hemochromatosis gene may contribute to the development of dilated cardiomyopathy that possibly is not mediated by a rise in serum iron (Mahon et al. 2000).

\section{Aluminum Toxicity}

Aluminum levels may be elevated in patients on hemodialysis. Although multifactorial, the mechanism of cardiac hypertrophy in patients with end-stage renal disease may involve direct aluminum cardiotoxicity (Reusche et al. 1996). Aluminum may be demonstrated by special stains in the myocardium of such patients. There is little reported evidence that aluminum toxicity plays a role in idiopathic dilated cardiomyopathy.

\section{Arsenic Toxicity}

Acute arsenic toxicity may result in a toxic myocarditis, and chronic exposure to arsenic, such as in occupational exposure, may cause chronic cardiomyopathy characterized by small vessel disease and interstitial inflammation with fibrosis (Hall and Harruff 1989).

\section{Miscellaneous}

Elevations of other potentially toxic metals have been demonstrated in heart tissue from patients with dilated cardiomyopathy. In addition to cobalt and mercury, these metals include antimony, gold, and chromium (Frustaci et al. 1999). The role of these elements in the pathogenesis of dilated cardiomyopathy remains to be elucidated.

\subsubsection{Atherosclerosis}

\subsubsection{Iron Excess}

The body has no method of controlling iron excretion; therefore, dietary excesses may lead to iron overload (Schumann 2001). The most likely excesses result from dietary supplements or alcoholic beverages brewed in iron containers (Schumann 2001). Genetic factors are also important in chronic iron overload (hemochromatosis). The medical literature covering the experimental and epidemiological relationship between excess iron stores and coronary artery disease has been recently reviewed (de Valk and Marx 1999). It has long been appreciated that males have a higher incidence of atherosclerosis than females and have greater body iron stores; however, a causative link between iron and atherosclerosis has not been fully established, and a recent prospective study has shown no relationship between iron stores (serum ferritin) and the development of ischemic heart disease (Sempos et al. 2000).

Experimental data support the role of iron in the process of lipid peroxidation, which is hypothesized to be involved in early stages of atherosclerosis. The exact mechanism by 
which endothelial cells and macrophages interact with iron and low-density lipoprotein are still unknown. There is speculation that catalytically active iron, in the form of nontransferrin-bound plasma iron and hemoglobin, oxidizes low-density lipoprotein to interact with the macrophage oxidized low-density lipoprotein receptor (Evans et al. 1995).

At a clinical level, the role of iron in lipid oxidation has been questioned. Some studies have failed to show an association between serum ferritin or dietary iron intake with markers of low-density lipoprotein oxidation (Iribarren et al. 1998). Several studies correlating body iron stores with clinically measured atherosclerosis have been positive (Kiechl et al. 1997), which demonstrates a synergistic effect with low-density lipoprotein levels. Other studies have been negative (Rauramaa et al. 1994). A recent review has demonstrated that the majority of studies correlating body iron stores with clinical assessments of atherosclerosis have not shown a significant correlation between clinical indices of coronary, carotid, or aortic atherosclerosis and body iron stores (Meyers 1996).

\subsubsection{Selenium Deficiency}

Like dilated cardiomyopathy, ischemic heart disease has been linked to low levels of serum selenium. The mechanism of selenium deficiency resulting in an increased risk of coronary artery disease is unknown but may be related to increased oxidative stress, as is the case with iron, or increased platelet aggregation (Salonen et al. 1988).

Epidemiological studies have provided some evidence for the role of selenium deficiency in the etiology of atherosclerotic disease. Angiographic studies suggest that low levels of selenium are associated with coronary stenosis (Yegin et al. 1997), and patients with acute myocardial infarction tend to have lower serum selenium compared to controls (NavarroAlarcon et al. 1999). Plasma, red blood cell, and urine selenium concentrations have been shown to be decreased in patients with acute myocardial infarction. The results of longitudinal studies within populations are conflicting (Huttunen 1997), however, and the risk of decreased levels of selenium appears to correlate with elevated low-density lipoprotein cholesterol. A nested case-control study among participants in the Physicians' Health Study showed no effect of selenium on the risk for acute myocardial infarction (Salvini et al. 1995). Other studies using toenail selenium concentration, which is a better measure of chronic selenium levels, have shown an inverse relationship between selenium and myocardial infarction only in Germany, which has relatively low levels of selenium (Kardinaal et al. 1997).

Salonen et al. (1982) showed an increase in overall cardiovascular morbidity and mortality for individuals with low serum selenium (less than $45 \mu \mathrm{g} / \mathrm{L}$ ), whereas Virtamo's group (1985) found no significant associations except for stroke mortality. A large prospective study in a Danish population demonstrated that men with the lowest tertile of blood selenium had a mildly increased risk for developing acute ischemic events of stroke or myocardial infarct (risk ratio of 1.7); this risk remained significant to a low level of probability ( $p=0.05$ ) when other risk factors were considered. This study also demonstrated a correlation between selenium and traditional risk factors, including tobacco smoking, social class, alcohol consumption, total cholesterol, hypertension, age, and physical inactivity (Suadicani et al. 1992). Other studies have found that selenium levels are affected by cigarette smoking and alcohol use, and that selenium is a negative acute phase reactant and may therefore be secondarily decreased by the inflammatory component of atherosclerosis. The current consensus is that the effect of selenium on ischemic heart disease is small and likely mediated by an association with other risk factors (Rayman 2000).

\subsubsection{Magnesium}

The majority of research related to magnesium and cardiovascular disease addresses magnesium physiology after acute myocardial infarction. Specifically, the role of intravenous magnesium in the treatment of acute myocardial infarction and the effects of magnesium levels or intake on the risk of acute myocardial infarction are controversial areas. Less attention has been paid to the effects of chronic intake of low magnesium because of environmental and natural geological factors and the effect of chronic magnesium supplementation on the incidence of acute coronary events. Low levels of magnesium and fluoride in drinking water were found to be associated with increased risk for acute myocardial infarction in Finland and Sweden. No such effect was found in England, where there was a small protective effect of magnesium in drinking water against death due to ischemic heart disease, but no protection against deaths due to acute myocardial infarction. Oral magnesium supplementation does not decrease the rate of subsequent cardiac events after myocardial infarction, and the level of serum magnesium is not related to morbidity in acute myocardial infarction patients.

\subsubsection{Calcium}

Calcium has a complex relationship with atherosclerosis, and it is frequently deposited in the extracellular matrix of advanced atherosclerotic plaques. There is no clear association between dietary calcium or serum levels of calcium and the risk for development of coronary atherosclerosis. High levels of serum calcium may have a mildly protective effect, because there is a borderline inverse relationship with serum calcium and the extent of coronary atherosclerosis (Narang et al. 1997). However, there is no clear association between calcium in drinking water and the incidence of deaths due to 
acute myocardial infarction deaths, as demonstrated in studies in England and Scandinavia (Maheswaran et al. 1999). (See Chap. 14, this volume.) An exception to these results is a study from Finland that demonstrated a protective effect of high levels of calcium in drinking water to fight against acute myocardial infarction in postmenopausal women (Rubenowitz et al. 1999).

\subsubsection{Other Metals}

The effects of trace elements on atherosclerosis are difficult to determine because of the complex interplay between metal levels and traditional risk factors for cardiovascular disease, such as disorders of blood lipids, blood pressure, coagulation, glucose tolerance, and circulating insulin. In addition, the relevance of serum metal levels, metal concentrations within blood cells, and analyses of metal content of portions of atherosclerotic plaque is often unclear.

Like iron, copper ions may exert oxidative stress on the arterial wall. Elevated copper within circulating white cells has been associated with atherosclerosis. Elevated serum copper has been related to peripheral vascular disease, especially when related to serum zinc levels. No consistent data show a link between zinc and atherogenesis. Pathologic studies have demonstrated elevated levels of zinc within fibrous plaques of the aorta (Mendis 1989). There is evidence that zinc requirements of the vascular endothelium are increased during inflammatory conditions such as atherosclerosis, where apoptotic cell death is also prevalent. Theoretically, zinc deficiency may exacerbate the detrimental effects of specific fatty acids and inflammatory cytokines on vascular endothelial functions, but an association between decreased dietary zinc and an increased risk for coronary atherosclerosis has yet to be demonstrated.

A mortality study of mercury miners in Europe demonstrated no increased deaths due to ischemic heart disease (Boffetta et al. 2001); however, in a prospective study among 1,014 men, high hair mercury content was one of the strongest predictors of the 4-year increase in the mean intima-media thickness, which is a measurement of carotid atherosclerosis (Salonen et al. 2000).

A study of chromium welders has suggested that welders exposed to chromium have increased plasma lipid oxidation (Elis et al. 2001). Although arsenic has been only indirectly associated with coronary heart disease, increased serum arsenic may lead to persistent oxidative stress, thereby theoretically leading to atherosclerosis.

\subsubsection{Hypertension}

\subsubsection{Lead}

The toxic effects of lead poisoning are well known; however, the effects of lower levels of lead exposure are uncertain. Although the finding is controversial, chronic low-level lead exposure has been linked to hypertension in both clinical and experimental studies. The exact pathogenic mechanisms that underlie the actions of lead in the cardiovascular system have yet to be elucidated definitively (Kopp et al. 1988).

There are a number of difficulties in proving a link between low-level exposure to lead (blood levels of $<1.45 \mu \mathrm{m} / \mathrm{L}$ or $<30 \mu \mathrm{g} / \mathrm{dL})$ and the development of high blood pressure. A number of possible covariates must be considered in epidemiologic studies, such as body mass index, alcohol consumption, other metals, race, and gender. Measurements of blood levels may not accurately reflect body stores, and there may be discrepant results depending on whether blood lead, bone lead, or urinary lead levels are obtained after chelation testing is performed. Several crosssectional epidemiologic studies have demonstrated an association between blood lead levels and hypertension in individuals without known occupational exposure and in men with occupational risk. In most of these studies, the association persists after correction for other variables. A similar number of studies have shown no association or only a very weak association between lead and hypertension, after adjustment for age and body mass index, in populations with or without known lead exposure. A study from the United States demonstrated an association only in AfricanAmericans, who had higher lead levels (Sokas et al. 1997). In a study of postpartum women in Los Angeles, an association between lead and hypertension was demonstrated only in immigrants who had, in general, higher levels than nonimmigrants. A study in Germany demonstrated a link only in heavy drinkers of alcohol; results from a crosssectional analysis of alcoholics in the United States also demonstrate a link between hypertension and blood lead levels. A metaanalysis of pooled data from several studies suggested only a weak positive association between blood pressure and lead exposure (Staessen et al. 1994).

Cross-sectional epidemiologic studies using bone indices have often shown a positive correlation between lead exposure and hypertension with an estimated relative risk of about 1.5 times for individuals with increased skeletal lead stores in men and women. These results, however, are not always confirmed by blood testing in the same patients, and results vary by bone site measured (e.g., patella vs. tibia). Studies estimating body stores of lead in measurements of blood and urine after a chelating challenge have also suggested a link between hypertension and increased lead stores, especially in the presence of renal failure (SanchezFructuoso et al. 1996).

In the United States and Western countries, mild blood pressure elevations due to moderate increases in lead blood levels translate into potentially large numbers of patients dying with coronary artery disease. This link between lead 
and coronary artery disease is corroborated by data showing a direct association between blood lead and electrocardiographic changes of left ventricular hypertrophy. There is evidence that occupational exposure to lead is associated with increased risk of dying from hypertension-related illness. A prospective study in Belgium, however, in which patients were followed for 6 years did not show any association between blood levels and hypertension, a finding that refutes a significant link between coronary heart disease and lead exposure (Staessen et al. 1996). The mechanisms by which lead may induce hypertension include increased vascular responsiveness to catecholamines mediated by effects on calcium channels and increased expression of endothelin and generation of reactive oxygen species.

Sources of lead exposure are numerous and include occupational exposure (workers in battery factories, smelters), environmental exposure (traffic exhaust, dust, paint chips, drinking water), cosmetics, food supplements, food preparation utensils, and illegal alcoholic beverages ("moonshine").

\subsubsection{Mercury}

Acute mercury poisoning may result in hypertension, but few data suggest that chronic low-level exposure to mercury is an etiologic factor in essential hypertension. Mortality statistics from mercury miners in several regions across Europe demonstrated no consistent increase in deaths due to hypertension (Boffetta et al. 2001), with the exception of Spain and Ukraine, which had elevated mortality ratios of 2.8 and 9.4, respectively, for hypertension-related diseases.

\subsubsection{Other Metals}

Chronic arsenic exposure from drinking water in contaminated wells has been implicated in a modest increased risk for hypertension in China and Bangladesh. Patients with hypertension, who are not on dialysis, may have elevated levels of serum aluminum, but an etiologic link has yet to be shown between hypertension and aluminum toxicity.

The effects of hypertension can ultimately lead to cardiac failure, resulting in increased venous backpressures. Depending on the severity of the failure, severe chronic congestive heart failure may lead to fibrosis of the liver. Direct toxicity of metal ions on the liver also may lead to injury to the liver and fibrosis of the liver, as is discussed in the final section.

\subsection{Hepatotoxicity of Metal Ions}

Several metals can injure the liver, but by far the most important are iron and copper. The diseases caused by metals may be genetic or acquired, and the effects can be acute or chronic (see Table 25.2). Acute metal toxicity produces hepatocellular and cholestatic injury:

1. Hepatocellular injury-Ferrous sulfate poisoning in children can lead to coagulative degeneration in zone 1 of the hepatic acinus, and phosphorus poisoning induces lytic necrosis in that zone, as well as steatosis. Copper toxicity causes zone 3 necrosis.

2. Cholestatic injury-Intrahepatic cholestasis has been reported with acute arsenical toxicity and as an idiosyncratic reaction to the use of gold salts for treatment of rheumatoid arthritis.

In chronic metal toxicity the injuries listed below are seen:

1. Vascular injury-Hepatoportal sclerosis is a recognized complication of chronic arsenical toxicity, for example, from ingestion of high levels of arsenic in drinking water (India, Bangladesh).

2. Chronic hepatitis-Chronic hepatitis is a stage in the evolution of Wilson's disease; hemosiderin is an accumulation in the liver in chronic hepatitis $\mathrm{C}$ which may lead to a poor response to interferon therapy.

3. Fibrosis and cirrhosis-Fibrosis and cirrhosis occur in genetic hemochromatosis, Wilson's disease, Indian childhood cirrhosis, acquired copper toxicosis, neonatal hemochromatosis, and sub-Saharan hemosiderosis; the presence of iron in nonalcoholic steatohepatitis may increase the hepatic injury and contribute to the fibrosis.

4. Granulomas-Chronic beryllium toxicity (berylliosis) in the past was associated with a sarcoidosis-like disease; exposure of vineyard sprayers to copper sulfate in Portugal has been reported to lead to granulomas in the lungs and liver.

5. Malignant tumors-Hepatocellular carcinoma is a dreaded complication of genetic hemochromatosis and, rarely, of Wilson's disease; angiosarcoma has been reported after chronic exposure to arsenic and rarely to iron or copper.

The hepatotoxicity of several metals, in alphabetical order, is discussed in more detail in the following paragraphs.

\subsubsection{Arsenic}

\subsubsection{Acute Toxicity}

Toxicity from inorganic arsenicals may result from attempts at homicide or suicide; exposure to insecticides, herbicides or rodenticides; industrial exposure; exposure to naturally contaminated materials; or from treatment with arsenical medications. The clinical features, mechanism of action, and other aspects of arsenical toxicity are comprehensively discussed in a review by Schoolmeester and White (1980). 
Table 25.2 Hepatotoxicity of metals

\begin{tabular}{|c|c|c|c|}
\hline Metal & Circumstances & Histopathology & Comments \\
\hline \multicolumn{4}{|c|}{ Acute toxicity } \\
\hline Iron & $\begin{array}{l}\text { Accidental ingestion by children (usually } \\
\mathrm{FeSO}_{4} \text { ) }\end{array}$ & Zone 1 necrosis & Also severe gastrointestinal injury \\
\hline Copper & Suicidal or accidental & Zone 3 necrosis & Also cholestasis \\
\hline \multicolumn{4}{|c|}{ Chronic toxicity } \\
\hline Iron & Genetic hemochromatosis & Hepatic hemosiderosis, fibrosis, cirrhosis, HCC & C282Y and H63D gene mutations \\
\hline \multicolumn{4}{|c|}{ Other (see Table 25.2) } \\
\hline \multirow[t]{4}{*}{ Copper } & Wilson's disease & $\begin{array}{l}\text { Copper overload, chronic hepatitis, cirrhosis, } \\
\text { fulminant liver failure with necrosis, HCC (rare) }\end{array}$ & ATP7B gene mutations \\
\hline & Indian childhood cirrhosis & Copper overload, Mallory bodies, fibrosis, cirrhosis & $\begin{array}{l}\text { Excess ingestion of copper in milk } \\
\text { from copper or brass containers }\end{array}$ \\
\hline & Endemic infantile & Copper overload, cirrhosis & \multirow{2}{*}{$\begin{array}{l}\text { Excess ingestion of copper in milk } \\
\text { plus genetic factor }\end{array}$} \\
\hline & Tyrolean cirrhosis & & \\
\hline
\end{tabular}

Arsenic Excess ingestion of arsenic via drinking Hepatoportal sclerosis, angiosarcoma water, drugs, or exposure to insecticides

Note: HCC hepatocellular carcinoma

Fig. 25.8 Arsenic-related angiosarcoma. (a) The malignant endothelial cells infiltrating the sinusoids have led to disruption of the liver cell plates (b); higher magnification of the angiosarcoma cells (b) shows marked nuclear pleomorphism and hyperchromasia

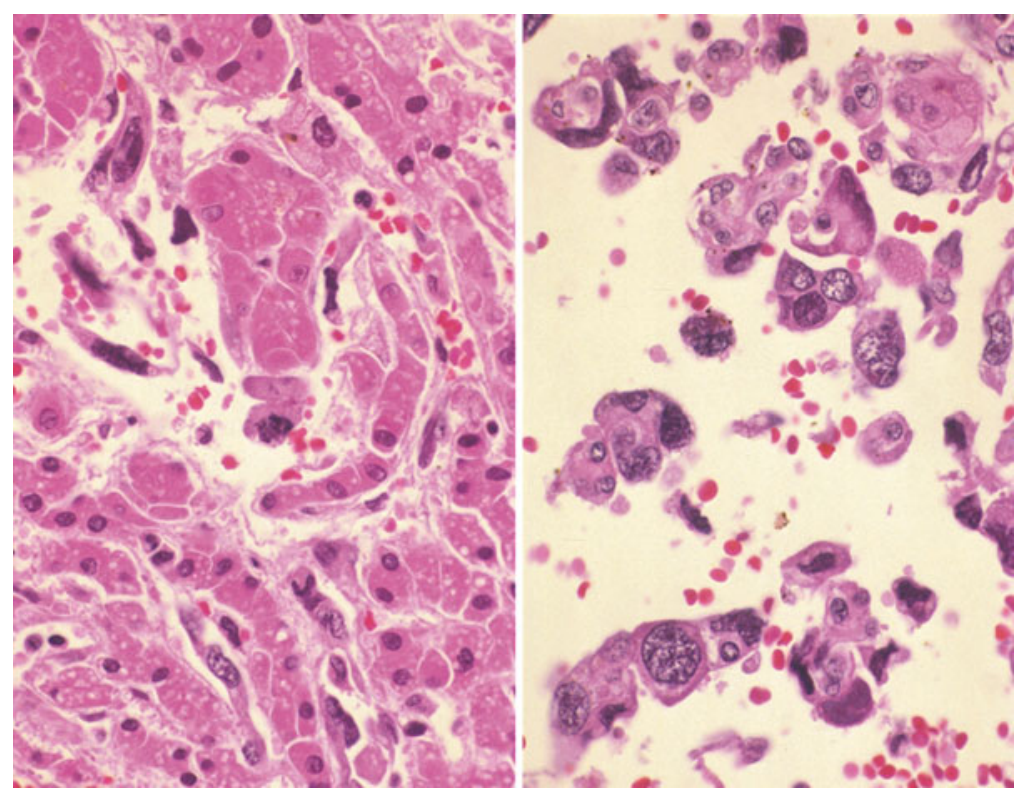

Hepatic injury is usually overshadowed by the effects of damage to other organ systems, such as the gastrointestinal, cardiovascular, neurologic, and hematologic ones. Observed histologic changes in the liver have included steatosis, cholestasis, and zone 3 necrosis. A striking increase in hepatocytic mitotic activity was noted in two cases reported by Brenard et al. (1996). Hepatic veno-occlusive disease following severe arsenic poisoning was described by Labadie et al. (1990). Predominantly cholestatic injury has been reported with the antiamebicidal agent carbarsome and the antisyphilitic drug arsphenamine. Acute arsenic and mercury intoxication has also resulted from ingestion of Indian ethnic remedies (Kew et al. 1993) and Chinese herbal balls (Espinoza et al. 1995). Experimental work with arsenates in rabbits was reported to cause periportal focal necrosis and cirrhosis of an unspecified type (Van Glahn et al. 1938).

\subsubsection{Chronic Toxicity}

Chronic arsenical injury to the liver can lead to hepatoportal sclerosis or noncirrhotic portal hypertension (Datta et al. 1979; Mazumder et al. 1988), cirrhosis (Denk et al. 1959; Lunchtrath 1972), systemic arterial disease (Rosenberg 1974), hepatocellular carcinoma (Jhaveri 1959), and angiosarcoma (Falk et al. 1981) (see Fig. 25.8). The chronic exposure was the result of therapy (e.g., the use of Fowler's 
solution [potassium arsenite] for the treatment of psoriasis), high levels of arsenic in drinking water, use of arsenical preparation as insecticides in vineyards, or industrial or environmental exposure (e.g., among workers in copper smelters or residents living nearby). The histologic changes that have been described in hepatoportal sclerosis include portal area expansion and fibrosis, an increase in the number of vessels in portal areas, thickening of portal vein branches (intimal thickening and muscular hypertrophy, but no thrombosis), and perisinusoidal fibrosis. The cirrhosis reported with chronic arsenicism has been described as "postnecrotic" or macronodular in type.

\subsubsection{Copper}

\subsubsection{Acute Copper Toxicity}

Acute copper toxicity may result from: (1) ingestion (either suicidal or accidental) of copper sulfate, (2) its use as an emetic or for the treatment of burns, (3) the release of copper ions from equipment made of copper, (4) acid $\mathrm{pH}$ conditions (e.g., malfunctioning hemodialysis equipment or vending machines), or (5) high levels of copper in drinking water (Blomfield et al. 1971; Spitainy et al. 1984; Holtzman et al. 1986). Copper poisoning leads to a hemolytic anemia related to several effects on erythrocytes that include inhibition of glucose-6-phosphate dehydrogenase activity, inhibition of glycolysis, denaturation of hemoglobin (with Heinz body formation), and oxidation of glutathione. The largest series of cases of acute poisoning with copper sulfate, ingested for suicidal purposes, was reported from New Delhi, India (Chuttani et al. 1965). Jaundice appeared on the second or third day in 11 of 48 patients (23.0\%). In five patients, the jaundice was deep, the liver was enlarged and tender, the average total serum bilirubin was $11.2 \pm 809 \mathrm{mg} / \mathrm{dL}$, the AST averaged $252.4 \pm 142$ units, and the prothrombin time was markedly prolonged. In the remaining six patients, the jaundice was mild, the serum bilirubin was about $3.0 \mathrm{mg} /$ $\mathrm{dL}$, and the AST averaged $144 \pm 80 \mathrm{IU}$. Histologic changes in biopsy or autopsy material showed zone three necrosis and cholestasis in the deeply jaundiced patients and focal necrosis or no changes in the mildly jaundiced patients. When measured, the serum copper levels have been markedly elevated in acute copper intoxication (Chuttani et al. 1965; Blomfield et al. 1971; Holtzman et al. 1986), as well as in the liver (Blomfield et al. 1971).

\subsubsection{Chronic Copper Toxicity}

Chronic copper toxicity can be hereditary or acquired. In humans, hereditary copper overload is exemplified by Wilson's disease and in animals by the copper toxicosis of the Long-Evans cinnamon rat; both conditions have an autosomal recessive inheritance and are not discussed in this review. Acquired forms of copper overload also occur in humans and animals. Sheep are particularly susceptible to copper intoxication, as they can be chronically exposed to excessive copper by grazing in sprayed orchards or by eating contaminated feed. The changes in sheep livers include steatosis, focal necrosis, swelling of liver and Kupffer cells, and cytochemically demonstrable copper in Kupffer cells (incorporated in lysosomes with lipofuscin), but Mallory bodies have not been observed. An interesting copper toxicosis was reported in North Ronaldsay sheep by Haywood et al. (2001). These sheep are a primitive breed that has adapted to a copper-impoverished environment in the Orkney Islands. Sheep transferred to copper-replete pastures on the mainland developed hepatic copper toxicity resembling that of Indian childhood cirrhosis and idiopathic copper toxicosis.

\section{Acquired Chronic Copper Toxicity}

In humans, acquired chronic copper toxicity may result from occupational environmental, or domestic exposure. An example of occupational exposure is the chronic exposure of vineyard workers to fungicide sprays containing copper sulfate. The resultant hepatic injury includes noncaseating granulomas, intraacinar and periportal fibrosis, cirrhosis, and, rarely, angiosarcoma (Pimental and Menezes 1977). The geological environment is the setting for Indian childhood cirrhosis, and a similar disease reported from outside the Indian subcontinent occurred in children who had ingested large quantities of copper in their drinking water.

\section{Indian Childhood Cirrhosis}

Indian childhood cirrhosis (ICC) is associated with marked hepatic copper overload. The copper storage has been demonstrated histochemically (by staining tissue sections with orcein for copper-binding protein and the rhodanine method for copper) and by quantitative techniques such as atomic absorption spectrophotometry. It is generally accepted that copper accumulation is directly responsible for the histopathologic lesions in ICC; these include the presence of numerous Mallory bodies, intraacinar and portal inflammation, copper accumulation (beginning in zone 1), periportal ductular proliferation, intraacinar and periportal fibrosis, occlusive lesions of terminal hepatic venules, and, eventually, the development of a micronodular cirrhosis (Smetana et al. 1961; Joshi 1987; Bhagwat et al. 1983) (see Fig. 25.9).

According to Bhagwat et al. (1983), cases of ICC have been reported from 17 countries as well as from the United States (Lefkowitch et al. 1982). The non-Indian cases also are characterized by marked copper overload and histopathologic alterations indistinguishable from those of ICC. In 1983, Tanner et al. (1983) pro-posed that increased 
Fig. 25.9 Indian childhood cirrhosis. (a) High magnification shows Mallory bodies in liver cells. (b) This cirrhotic liver is composed of nodules separated by fibrous septa (Masson)

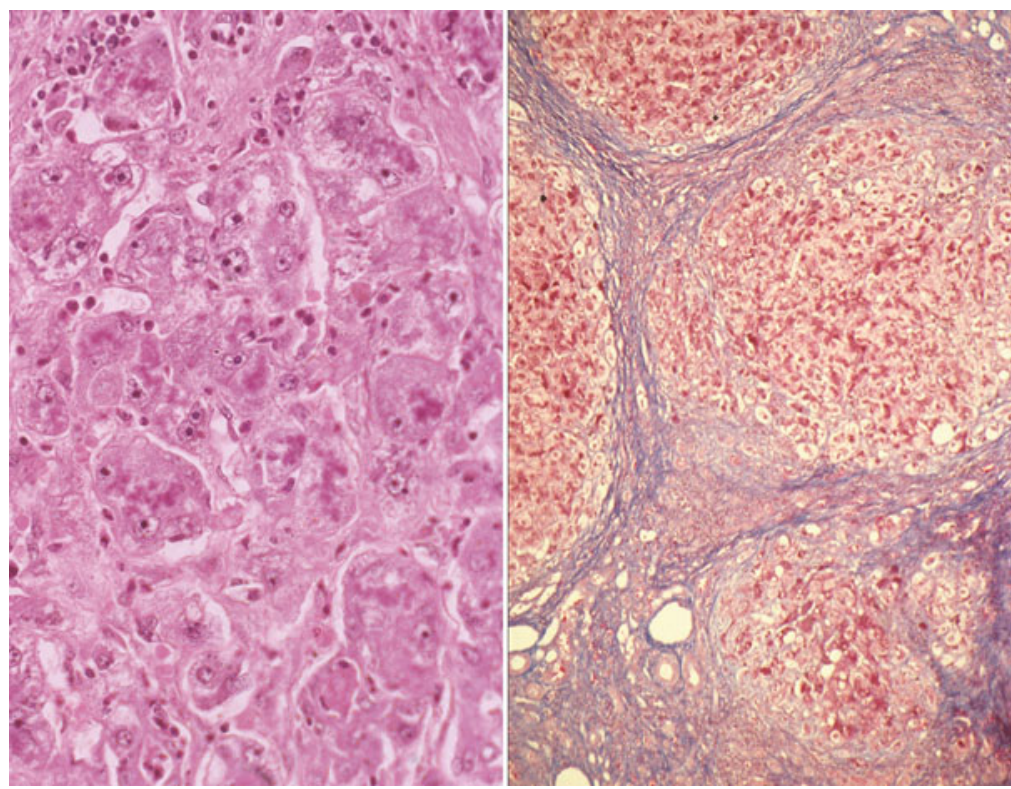

dietary copper (from copper-contaminated milk stored in brass and copper containers) could be of etiologic significance in ICC. Subsequently, O'Neill and Tanner (1989) demonstrated experimentally that copper (but not zinc) is avidly taken up from brass and bound to casein from which it is completely removable by picolinate chelation. They concluded that milk is an effective carrier of copper from a brass utensil to the infant enterocyte. Lending support to a direct cytopathic effect of copper are recent reports of clinical recovery, improved survival, and reversal of the hepatic histological lesions by penicillamine therapy of infants with ICC (Tanner et al. 1987; Bhusnurmath et al. 1991).

Of great interest are reports of several children who developed an illness, clinically and histopathologically resembling ICC, from the chronic ingestion of well water contaminated with high levels of copper (Müller-Höcker et al. 1985, 1987; Schramel et al. 1988). In all cases, the copper was leached from copper pipes into drinking water delivered to the children's homes. Early exposure to copper appears to be crucial, because siblings exposed after 9 months of age and the parents who drank the same water did not develop the disease (Müller-Höcker et al. 1985; Schramel et al. 1988). Other cases of "non-Indian childhood cirrhosis," also referred to as "idiopathic hepatic copper toxicosis," not specifically related to increased dietary copper intake have been reported (Maggiore et al. 1987; Horslen et al. 1994; Ludwig et al. 1995). To date, most of the affected children have succumbed to liver failure. It is conceivable that some cases of ICC occurring outside the Indian subcontinent are examples of environmental chronic copper toxicity, but other cases are not. The occurrence of the disease in siblings and parental consanguinity in two cases suggest a genetic abnormality, possibly an autosomal recessive disorder (Scheinberg and Sternlieb 1994). Lack of support for excess dietary copper as a cause of non-Indian childhood cirrhosis comes from a study of Scheinberg and Sternlieb (1994) in which no liverrelated deaths were found in children less that 6 years of age in three Massachusetts towns with high copper concentrations in drinking water. The study covered 64,124 child-years of exposure. Of relevance to these observations are cases of endemic Tyrolean infantile cirrhosis, which is transmitted by autosomal recessive inheritance but requires an additional risk factor such as excess dietary copper (from cows' milk contaminated with copper leached from untinned copper or brass containers) for its expression (Müller et al. 1996). The disease was eradicated when the untinned copper containers were replaced by modern industrial vessels.

Before leaving this section, it is worth noting that chronic acquired copper toxicity in the adult is very rare. There is one report of chronic toxicity from massive ingestion of copper coins; 275 copper coins were found at autopsy in the stomach of a mentally deranged person (Yelin et al. 1987). Corrosion of the coins led to absorption of copper from the stomach, resulting in liver and kidney injury. The changes in the liver resembled those of ICC and childhood hepatic copper toxicosis. It is important to remember that accumulation of copper occurs in a number of chronic cholestatic conditions, most frequently in primary biliary cirrhosis and primary sclerosing cholangitis. Although demonstration of the stored copper, mainly periportal, is of diagnostic value, it does not appear to be a risk factor for progression of the disease, and attempts at removing the copper by penicillamine therapy have been abandoned. 


\subsubsection{Iron}

Injury to the liver by iron can be either acute or chronic. Genetic hemochromatosis, the most common inherited metabolic disease, is not discussed here; instead, the focus of this section is on acquired iron toxicity, which may be acute or chronic.

\subsubsection{Acute Iron Toxicity}

Accidental overdose of iron-containing drugs and dietary supplements (in tablet or capsule form) is a leading cause of fatal poisoning of children under 6 years of age (Nightingale 1997), but occasional cases have been reported in adults (Monoguerra 1976). Since 1986, U.S. poison control centers have received reports of more than 110,000 incidents of children younger than 6 years accidentally swallowing iron tablets. Almost $17 \%$ of pediatric deaths reported to poison control centers between 1988 and 1992 were due to iron poisoning, compared with $12 \%$ between 1984 and 1987 . Death has occurred from ingesting as little as $200 \mathrm{mg}$ to as much as $5.85 \mathrm{~g}$ of iron (Nightingale 1997).

A large number of products available in pharmacies, foodstores, and discount stores contain iron, and the problem is compounded by the attractiveness of dosage forms, high availability, and ambiguous labeling (Krenzelok and Hoff 1979). The Food and Drug Administration (FDA) issued a regulation, effective July 15, 1997, with labeling and packaging requirements to protect children from accidental poisoning from iron-containing drugs and dietary supplements in tablet or capsule form. Under the regulation, these products must display-in a prominent and conspicuous place set off by surrounding lines - the following warning statement: "WARNING: Accidental overdose of ironcontaining products is a leading cause of fatal poisoning in children under 6. Keep this product out of reach of children. In case of accidental overdose, call a doctor or poison control center immediately" (Nightingale 1997). In addition, the agency requires most products that contain $30 \mathrm{mg}$ or more of iron per dosage, such as iron tablets or capsules for pregnant women, to be packaged as individual doses (for example, in blister packages). The FDA has concluded that this packaging will limit the number of unit doses that a child may consume once access is gained to the product, thus significantly reducing the likelihood of serious injury.

Although the morbidity of acute iron poisoning is high, the mortality in two large series was low-none in the series of 66 patients reported by James (1970), and $5.16 \%$ of the 172 cases reported by Westlin (1966). The typical victim of iron poisoning vomits within $10 \mathrm{~min}$ to $1.5 \mathrm{~h}$ after swallowing a toxic dose of iron; consequently, it is often difficult to state what the toxic dose is. In a severe case that does not prove fatal, the three stages of poisoning are:
- First stage-This stage lasts approximately $6 \mathrm{~h}$ and begins with abdominal pain, nausea, and vomiting and goes on to hematemesis, melena, and subsequently shock and possibly coma.

- Second stage-This stage is one of apparent recovery during which toxic iron compounds are formed.

- Third stage-This stage begins about $24 \mathrm{~h}$ after ingestion of the toxic dose. Acidosis and hyperglycemia develop, and there may be convulsions, coma, bleeding, and evidence of hepatic damage. Invariably, edema and necrosis of the gastric mucosa are found in fatal cases. If the child recovers, there may be fibrosis of the gastric mucosa leading to pyloric stenosis.

Gandhi and Robarts (1962) reviewed 11 such cases. The interval between the time of ingestion of the ferrous sulfate and the symptoms of obstruction ranged from 13 to 40 days. Pyloric stenosis was present in five patients. "Hourglass" stricture of the stomach was found in the other six children, two of whom had pyloric stenosis as well; one child also had a penetrating gastric ulcer that involved the liver.

Nearly $90 \%$ of deaths from iron poisoning occur in the first $48 \mathrm{~h}$ after ingestion. Pathologic findings include widespread necrosis of the upper gastrointestinal tract (see Fig. 25.10), thrombosis of intestinal vessels, periportal (zone 1) necrosis of hepatic cells, hemorrhagic pneumonia, and pericardial effusion. Liver cells in zone 1 show coagulative degeneration with nuclear pyknosis or karyorrhexis, and there is variable drop out of cells (Pestaner et al. 1999) (see Fig. 25.11). The inflammatory response is typically minimal, but there may be a sprinkling of neutrophils and lymphocytes. Histochemical stains for iron often show positive staining of the coagulated cells and damaged sinusoids.

\subsubsection{Chronic Iron Toxicity}

Numerous conditions, other than genetic hemochromatosis, can lead to chronic accumulation of iron in the liver. Among these are the hereditary anemias listed in Table 25.3. In transfusion-dependent $\beta$-thalassemia major, the iron overload is severe and, over a period of months or years, can lead to congestive heart failure, hypothyroidism, diabetes mellitus, hepatomegaly, fibrosis, and cirrhosis (Modell 1975; Schafer et al. 1981). In transfusional siderosis, iron initially accumulates in reticuloendothelial cells but eventually storage also occurs in parenchymal cells, beginning in zone 1. A large amount of iron also is found in the spleen, in contrast to genetic hemochromatosis (Oliver 1959).

Iron overload has been reported in a number of inherited metabolic diseases, including hereditary tyrosinemia, Zellweger's syndrome, congenital atransferrinemia, aceruloplasminemia, Wilson's disease after penicillamine therapy (Shiono et al. 2001), porphyria cutanea tarda, and 
Fig. 25.10 Acute ferrous sulfate toxicity: (a) small intestine showing marked necrosis of the villi; (b) iron encrustation (blue) of the necrotic intestinal villi (Prussian blue stain)

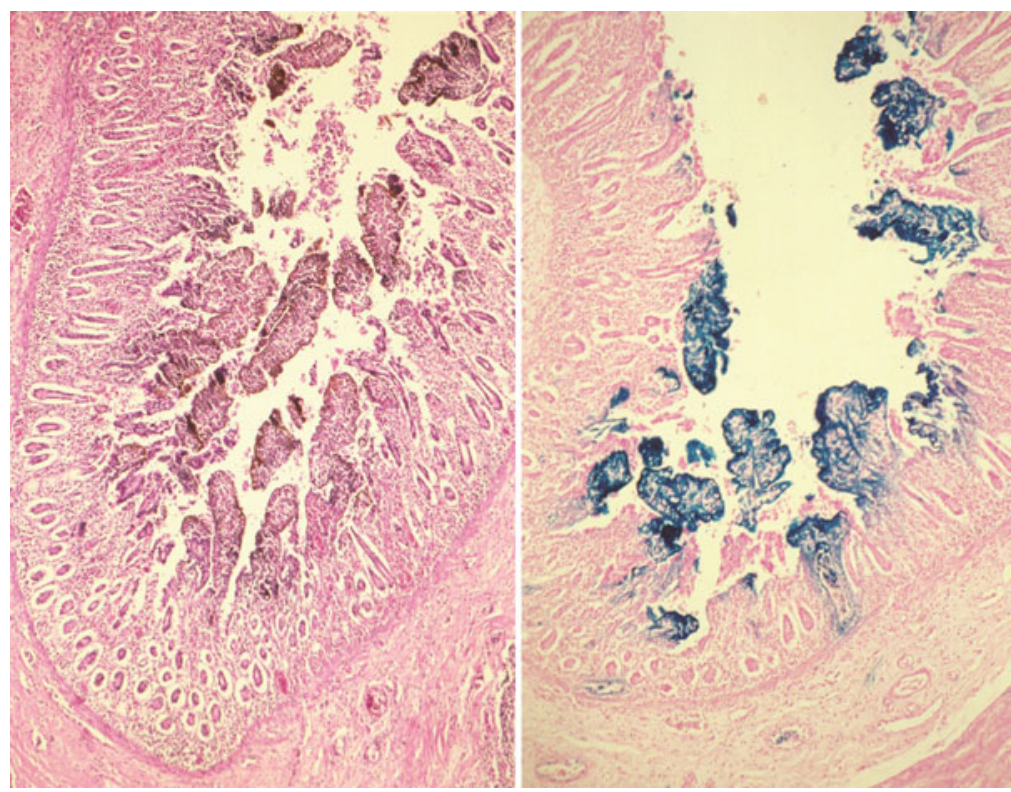

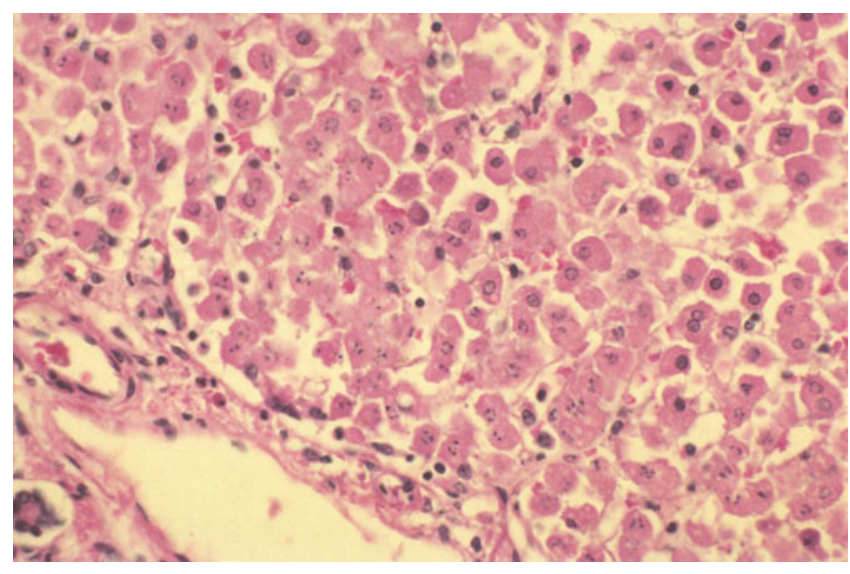

Fig. 25.11 Acute ferrous sulfate toxicity; section of the liver of the same patient illustrated in Fig. 25.10 shows coagulative degeneration and dissociation of liver cells in zone 1. A portal area is present in the lower left corner

alpha-1 antitrypsin (AAT) deficiency. In the last condition, no association between genetic hemochromatosis and AAT deficiency was found in one study (Fargion et al. 1996). In another study, the association of AAT deficiency and genetic hemochromatosis led to an earlier onset of cirrhosis in genetic hemochromatosis, but it did not increase the risk of hepatocellular carcinoma (Elzouki et al. 1995). In porphyria cutanea tarda, $60-70 \%$ of patients have mild to moderate iron overload, and approximately $10 \%$ have increases in the range of genetic hemochromatosis; the major cause is the presence of mutations of the HFE gene (Bonkovsky and Lambrecht 2000). Hepatic iron accumulation can occur in a number of acquired diseases of the liver (Table 25.3). The ones discussed briefly here are chronic hepatitis C, nonalcoholic and alcoholic steatohepatitis, cirrhosis, and post-portacaval shunt surgery.

Hepatic iron accumulation occurs in chronic hepatitis C. In one study from Italy, $10 \%$ of patients with chronic hepatitis $\mathrm{C}$ had an elevated hepatic iron content (Riggio et al. 1997). Stainable iron in sinusoidal cells and portal tracts reflects an increased hepatic iron concentration, and elevated serum iron values have been linked to poor responses of chronic hepatitis $\mathrm{C}$ to interferon therapy. In one study, hepatic iron accumulation was found to be significantly associated with histologic activity and cirrhosis (Hezode et al. 1999). Barton et al. (1995) have suggested that the percentage of portal areas staining for iron should be included in the pathology report of liver biopsies; these investigators found that patients who respond to interferon therapy have less than $40 \%$ portal areas positive for iron. Enhanced iron accumulation and lipid peroxidation were improved by interferon therapy in one study (Kageyama et al. 2000). Pirisi et al. (2000) believed that interface hepatitis (piecemeal necrosis) and its sequelae (sinusoidal capillarization and microshunting) are major factors in iron deposition in chronic hepatitis C. HFE mutations are not responsible for the iron deposition but could favor the progression of virus-induced damage independently from interference with iron metabolism. The topic of iron and its relationship to chronic viral hepatitis is reviewed in detail by Bonkovsky et al. (1996, 1999).

Patients with heavy alcohol consumption and genetic hemochromatosis $(\mathrm{GH})$ have a higher prevalence of cirrhosis than those who do not. Ludwig et al. (1997) found that subjects with GH who drank more than $60 \mathrm{~g}$ of alcohol per day were approximately nine times more likely to develop cirrhosis than those who drank less than that amount. The range of the hepatic iron concentration associated with 
Table 25.3 Causes of hepatic iron overload not related to genetic hemochromatosis

\begin{tabular}{|c|c|}
\hline Etiology & Ref. \\
\hline \multicolumn{2}{|l|}{ Hereditary anemias } \\
\hline Sickle cell anemia & Searle et al. (2001) \\
\hline \multicolumn{2}{|l|}{ Thalassemia major } \\
\hline \multicolumn{2}{|l|}{ Sideroblastic anemia } \\
\hline Hereditary spherocytosis & Barry et al. (1968) \\
\hline \multicolumn{2}{|l|}{ Chronic liver disease } \\
\hline Chronic hepatitis C & Hezode et al. (1999) and Ganne-Carrié et al. (2000) \\
\hline Alcoholism and alcoholic liver disease & Kageyama et al. (2000) \\
\hline Nonalcoholic steatohepatitis & George et al. (1998), Younossi et al. (1999) and Bonkovsky and Lambrecht (2000) \\
\hline Cirrhosis or diverse etiology & Deugnier et al. (1997) and Ludwig et al. (1997) \\
\hline Post-portacaval shunt & Bonkovsky et al. (1996) \\
\hline \multicolumn{2}{|l|}{ Increased oral or parenteral iron loading } \\
\hline African iron overload (dietary overload with genetic factor) & $\begin{array}{l}\text { Gordeuk et al. (1986, 1992), Gangaidzo and Gordeuk (1995) and Mandishona et al. } \\
\text { (1998) }\end{array}$ \\
\hline $\begin{array}{l}\text { African-American iron overload (similar to African iron } \\
\text { overload) }\end{array}$ & Barton et al. $(1995 \mathrm{a}, \mathrm{b})$ \\
\hline Medicinal iron ingestion & Hennigar et al. (1979) \\
\hline Transfusional siderosis & Oliver (1959) and Schafer et al. (1981) \\
\hline Hemodialysis & Gokal et al. (1979) \\
\hline \multicolumn{2}{|l|}{ Inherited metabolic diseases } \\
\hline$\alpha-1$ Antitrypsin deficiency with genetic hemochromatosis & Elzouki et al. (1995); Fargion et al. (1996) \\
\hline Porphyria cutanea tarda & Bonkovsky and Lambrecht (2000) \\
\hline \multicolumn{2}{|l|}{ Hereditary tyrosinemia } \\
\hline \multicolumn{2}{|l|}{ Zellweger's syndrome } \\
\hline Congenital atransferrinemia & Searle et al. (2001) \\
\hline Aceruloplasminemia & Andrews (1999) \\
\hline Wilson's disease, especially after penicillamine therapy & Shiono et al. (2001) \\
\hline Neonatal hemochromatosis? & Bonkovsky et al. (1996) \\
\hline
\end{tabular}

cirrhosis (in the absence of other cofactors) was 237-675 $\mu \mathrm{mol} / \mathrm{g}$ dry weight.

Iron overload in cirrhosis was studied in 447 native livers by Ludwig et al. (1997) and Deugnier et al. (1997). It is very common in many types of nonbiliary cirrhosis and appears to be acquired and to occur rapidly once cirrhosis develops (Ludwig et al. 1997). Quantitative iron determinations cannot be relied on to differentiate such cases from GH. Patients with nonalcoholic cirrhosis can accumulate iron (and zinc) after end-to-side portacaval shunting, but quantitative iron analyses have shown that such patients have far less iron than patients with $\mathrm{GH}$, and they are unlikely to have tissue injury resulting from the iron overload (Adams et al. 1994).

Nonalcoholic steatohepatitis (NASH), now sometimes referred to as nonalcoholic fatty liver disease, may be accompanied by iron overload. In one study of 65 patients from the United States, iron accumulation, when present, was not associated with increased overall mortality, liverrelated mortality, or cirrhosis (Younossi et al. 1999). Bonkovsky et al. (1999) found increased prevalence of HFE mutations in 57 subjects with NASH. Those with C282Y mutations had significantly higher levels of serum
ALT and greater hepatic fibrosis than those without. In another study of 51 patients with NASH from Australia, the $\mathrm{C} 282 \mathrm{Y}$ mutation was found to be responsible for most of the mild iron overload, and it was significantly associated with hepatic damage in these patients (George et al. 1998). It was suggested that phlebotomy therapy to remove the increased iron stores could delay or even reverse the liver damage.

African iron overload (formerly referred to as Bantu siderosis) is now rare in South Africa but remains a public health issue in sub-Saharan Africa (Gordeuk et al. 1986). It appears to be caused by an interaction between the amount of dietary iron (consumed in traditional beer brewed in steel drums) and a gene distinct from any HLA-linked gene (Gordeuk et al. 1992). African iron overload is considered a risk factor for hepatocellular carcinoma in black Africans (Gangaidzo and Gordeuk 1995; Mandishona et al. 1998). Iron overload in African-Americans (that is unexplained by dietary or medicinal iron excess, transfusions, or sideroblastic anemia) is considered to be similar to that in sub-Saharan Africans (Barton et al. 1995a, b).

Miscellaneous effects of iron overload that should be briefly mentioned include impaired cellular immune 
function and increased susceptibility to bacterial infections (Bonkovsky et al. 1996), as well as hepatocellular carcinoma (HCC). The occurrence of HCC in patients with genetic hemochromatosis and cirrhosis is too well recognized to require comment, but iron may play a putative role in HCC that occurs rarely in a noncirrhotic liver (Turlin et al. 1995).

Acknowledgements The authors would like to express their appreciation to Drs. Elena Ladich, Todor Todorov, Leonor Martinez, Elizabeth Meze, and Linda Murakata for their valuable contributions during the preparation of this chapter.

\section{Further Reading}

Adams PC, Bradley C, Frei JV (1994) Hepatic iron and zinc concentrations after portacaval shunting for nonalcoholic cirrhosis. Hepatology 19:101-105

American Thoracic Society (1986) The diagnosis of nonmalignant diseases related to asbestos. Am Rev Respir Dis 134:363-368

Andrews N (1999) Disorders of iron metabolism. N Engl J Med 341:1886-1995

Barchowsky A, Dudek EJ, Treadwell MD, Wetterhahn KE (1996) Arsenic induces oxidant stress and NFKB activation in cultured aortic endothelial cells. Free Radic Biol Med 21:783-790

Barnhart S, Thornquist M, Omenn G et al (1990) The degree of roentgenographic parenchymal opacities attributable to smoking among asbestos-exposed subjects. Am Rev Respir Dis 141:1102-1106

Barrett JC, Lamb PW, Wang TC, Lee TC (1989) Mechanisms of arsenic-induced cell transformation. Biol Trace Elem Res 21:421-429

Barry M, Scheuer PJ, Sherlock S et al (1968) Hereditary spherocytosis with secondary haemochromatosis. Lancet 2:481-485

Barton AL, Banner BF, Cable EE et al (1995a) Distribution of iron in the liver predicts the response of chronic hepatitis $\mathrm{C}$ infection to interferon therapy. Am J Clin Pathol 103:419-424

Barton JC, Edwards CQ, Bertoli LF et al (1995b) Iron overload in African Americans. Am J Med 99:616-623

Becklake M (1983) Occupational lung disease: past record and future trend using the asbestos case as an example. Clin Invest Med 6:305-337

Belton JC, Benson NC, Hanna ML, Taylor RT (1985) Growth inhibition and cytotoxic effects of three arsenic compounds on cultured Chinese hamster ovary cells. J Environ Sci Health 20A:37-72

Bhagwat AG, Walia BN, Koshy A, Banerji CK (1983) Will the real Indian childhood cirrhosis please stand up? Cleve Clin Q 50:323-337

Bhusnurmath SR, Walia BNS, Singh S et al (1991) Sequential histopathologic alterations in Indian childhood cirrhosis treated with Dpenicillamine. Hum Pathol 22:653-658

Blomfield J, Dixon SR, McCredie DA (1971) Potential hepatotoxicity of copper in recurrent hemodialysis. Arch Intern Med 128:555-560

Boffetta P, Sallsten G, Garcia-Gomez M, Pompe-Kirn V, Zaridze D, Bulbulyan M, Caballero JD, Ceccarelli F, Kobal AB, Merler E (2001) Mortality from cardiovascular diseases and exposure to inorganic mercury. Occup Environ Med 58:461-466

Bonkovsky HL, Lambrecht RW (2000) Iron-induced liver injury. Clin Liver Dis 4:409-429

Bonkovsky HL, Banner BF, Lambrecht RW, Rubin RB (1996) Iron in diseases other than hemochromatosis. Semin Liver Dis 16:65-82
Bonkovsky HL, Jawaid Q, Tortorelli K et al (1999) Non-alcoholic steatohepatitis and iron; increased prevalence of mutations of the HFE gene in non-alcoholic steatohepatitis. J Hepatol 31:421-429

Brain J, Valberg P (1979) Deposition of aerosol in the respiratory tract. Am Rev Respir Dis 120:1325-1373

Brenard R, Laterre PF, Reynaert M et al (1996) Increased hepatocytic mitotic activity as a diagnostic marker of acute arsenic intoxication. J Hepatol 25:218-220

Browne K (1986) A threshold for asbestos related lung cancer. Br J Ind Med 43:556-558

Browne K (1994) Asbestos-related disorders. In: Parkes W (ed) Occupational lung disorders. Butterworth-Heinemann, Oxford

Cavanagh JB, Nolan CC (1994) The neurotoxicity of organolead and organotin compounds. In: de Wolff FA (ed) Handbook of clinical neurology, vol 20. Elsevier, Amsterdam, pp 129-150

Cavigelli M, Li WW, Lin A, Su B, Yushioka K, Karin M (1996) The tumor promoter arsenite stimulates AP-1 activity by inhibiting a JNK phosphatase. EMBO J 15:6269-6279

Centeno JA, Pestaner JP, Mullick FG, Virmani R (1996) An analytical comparison of cobalt cardiomyopathy and idiopathic dilated cardiomyopathy. Biol Trace Elem Res 55:21-30

Chan P, Huff J (1997) Arsenic carcinogenesis in animals and in humans: mechanistic, experimental, and epidemiological evidence. Environ Carcinog Ecotoxicol Rev 15:83-122

Chen CJ, Chen CW, Wu MM, Kuo TL (1992) Cancer potential in liver, lung, bladder, and kidney due to ingested inorganic arsenic in drinking water. Br J Cancer 66:888-892

Choie DD, Richter GW (1972) Lead poisoning: rapid formation of intranuclear inclusions. Science 177(55):1194-1195

Chou HT, Yang HL, Tsou SS, Ho RK, Pai PY, Hsu HB (1998) Status of trace elements in patients with idiopathic dilated cardiomyopathy in central Taiwan. Chung Hua I Hsueh Tsa Chih (Taipei) 61:193-198

Chung C, Tsai R, Chen G, Yu H, Chai C (1998) Expression of bcl-2, p53 and Ki-67 in arsenical skin cancers. J Cutan Pathol 25:457-462

Churg A (1998a) Non-neoplastic disease caused by asbestos. In: Churg A, Green F (eds) Pathology of occupational lung disease. Williams \& Wilkins, Baltimore

Churg A (1998b) Neoplastic asbestos-induced disease. In: Churg A, Green F (eds) Pathology of occupational lung disease. Williams \& Wilkins, Baltimore

Churg A, Colby T (1998) Diseases caused by metals and related compounds. In: Churg A, Green F (eds) Pathology of occupational lung disease. Williams \& Wilkins, Baltimore

Churg A, Warnock M (1981) Asbestos and other ferruginous bodies. Am J Pathol 102:447-456

Churg A, Wright J, Vedal S (1993) Fiber burden and patterns of asbestos-related disease in chrysotile miners and millers. Am Rev Respir Dis 148:25-31

Chuttani HK, Gupta PS, Gulati S, Gupta DN (1965) Acute copper sulfate poisoning. Am J Med 39:849-854

Craighead J, Abraham J, Churg A et al (1982) The pathology of asbestos-associated diseases of the lungs and pleural cavities: diagnostic criteria and proposed grading schema (report of the pneumoconiosis committee of the college of American pathologists and the national institute for occupational safety and health). Arch Pathol Lab Med 106:544-596

Datta DV, Mitra SK, Chhuttani PN, Chakravarti RN (1979) Chronic oral arsenic intoxication as a possible aetiological factor in idiopathic portal hypertension (non-cirrhotic portal fibrosis) in India. Gut 20:378-384

de Valk B, Marx JJ (1999) Iron, atherosclerosis, and ischemic heart disease. Arch Intern Med 159:1542-1548

Denk R, Holzmann H, Lange HJ, Greve D (1959) Uber Arsenspatschaden bei obduzierten Moselwinzern. Med Welt 11:557-567

Deugnier Y, Turlin B, Le Quilleue D et al (1997) A reappraisal of hepatic siderosis in patients with end-stage cirrhosis: practical 
implications for the diagnosis of hemochromatosis. Am J Surg Pathol 21:669-675

1999 Diseases of immunity. In: Cotran R, Kumar V, Collins T (eds) Pathologic basis of disease. W. B. Saunders, Philadelphia, pp 188-259

Doll R (1993) Mortality from lung cancer in asbestos workers 1955 (classical article). Br J Ind Med 50:485-490

Dupres J, Mustard J, Uffen R (1984) Report of the royal commission on matters of health and safety arising from the use of asbestos in Ontario. Queen's Printer for Ontario, Toronto

Elis A, Froom P, Ninio A, Cahana L, Lishner M (2001) Employee exposure to chromium and plasma lipid oxidation. Int $\mathrm{J}$ Occup Environ Health 7:206-208

Elzouki A-NY, Hulterantz R, Stäl P et al (1995) Increased PiZ frequency for $\alpha-1$ antitrypsin in patients with genetic hemochromatosis. Gut 36:922-926

Epler G, McLoud T, Gaensler E (1982) Prevalence and incidence of benign asbestos pleural effusion in a working population. JAMA 247:617-622

Espinoza EO, Mann MJ, Bleasell B (1995) Arsenic and mercury in traditional Chinese herbal balls (letter). $\mathrm{N}$ Engl J Med 333:803-804

Evans PJ, Smith C, Mitchinson MJ, Halliwell B (1995) Metal ion release from mechanically disrupted human arterial wall Implications for the development of atherosclerosis. Free Radic Res 23:465-469

Falk H, Caldwell GG, Ishak KG et al (1981) Arsenic-related hepatic angiosarcoma. Am J Ind Med 2:43-50

Fargion S, Bissoli F, Fracanzani AL et al (1996) No association between genetic hemochromatosis and $\alpha-1$ antitrypsin deficiency. Hepatology 24:1161-1164

Fraser R, Muller N, Colman N et al (1999a) Pleural effusion. In: Fraser and Pare's diagnosis of diseases of the chest. W. B. Saunders, Philadelphia

Fraser R, Muller N, Colman N et al (1999b) Inhalation of inorganic dust (pneumoconiosis). In: Fraser and Pare's diagnosis of diseases of the chest. W. B. Saunders, Philadelphia

Frustaci A, Magnavita N, Chimenti C, Caldarulo M, Sabbioni E, Pietra R, Cellini C, Possati GF, Maseri A (1999) Marked elevation of myocardial trace elements in idiopathic dilated cardiomyopathy compared with secondary cardiac dysfunction. J Am Coll Cardiol 33:1578-1583

Gandhi RK, Robarts FH (1962) Hourglass stricture of the stomach and pyloric stenosis due to ferrous sulphate poisoning. Br J Surg 49:613-617

Gangaidzo IT, Gordeuk VK (1995) Hepatocellular carcinoma and African iron overload. Gut 37:727-730

Ganne-Carrié N, Christidis C, Chastang C et al (2000) Liver iron is predictive of death in alcoholic cirrhosis: a multivariate study of 229 consecutive patients with alcoholic and/or hepatitis $\mathrm{C}$ virus cirrhosis: a prospective followup study. Gut 46:277-282

Ge K, Yang G (1993) The epidemiology of selenium deficiency in the etiological study of endemic diseases in china. Am J Clin Nutr 57:259S-263S

Ge K, Xue A, Bai J, Wang S (1983) Keshan disease-an endemic cardiomyopathy in China. Virchows Arch A Pathol Anat Histopathol 401:1-15

George DK, Goldwurm S, MacDonald GA et al (1998) Increased hepatic iron concentration in non-alcoholic steatohepatitis is associated with increased fibrosis. Gastroenterology 114:311-318

Ghadially FN (1979) Ultrastructural localization and in situ analysis of iron, bismuth, and gold inclusions. CRC Crit Rev Toxicol 6 (4):303-350

Gibbs A (1996) Occupational lung disease. In: Hasleton P (ed) Spencer's pathology of the lung. McGraw-Hill, New York
Gokal R, Millard PR, Weatherall DJ et al (1979) Iron metabolism in haemodialysis patients. Q J Med 48:369-391

Good PF et al (1992a) Selective accumulation of aluminum and iron in the neurofibrillary tangles of Alzheimer's disease: a laser microprobe (LAMMA) study. Ann Neurol 31:286-292

Good PF, Olanow CW, Perl DP (1992b) Neuromelanin-containing neurons of the substantia nigra accumulate iron and aluminum in Parkinson's disease: a LAMMA study. Brain Res 593:343-346

Gordeuk VR, Boyd RD, Brittenham GM (1986) Dietary iron overload in rural Sub-Saharan Africa. Lancet 1:1310-1313

Gordeuk V, Mukübi SJ, Hasstedt SJ et al (1992) Iron overload in Africa: interaction between a gene and dietary iron content. N Engl J Med 326:95-100

Greenberg S, Roggli V (1992) Carcinoma of the lung. In: Roggli V, Greenberg S, Pratt P (eds) Pathology of asbestos-associated disease. Little Brown \& Company, Boston

Hall JC, Harruff R (1989) Fatal cardiac arrhythmia in a patient with interstitial myocarditis related to chronic arsenic poisoning. South Med J 82:1557-1560

Hanada K, Hashimoto I, Kon A, Kida K, Mita R (1998) Silver in sugar particles and systemic Argyria. Lancet 351:960

Haywood S, Müller T, Müller W et al (2001) Copper-associated liver disease in north ronaldsay sheep: a possible animal model for nonwilsonian hepatic copper toxicosis of infancy and childhood. J Pathol 195:264-269

Helwig E (1951) Chemical (beryllium) granulomas of the skin. Mil Surg 109:540-558

Hennigar GR, Greene WB, Walker EM et al (1979) Hemochromatosis caused by excessive vitamin iron intake. Am J Pathol 96:611-624

Hezode C, Cazeneuve C, Coué O et al (1999) Liver iron accumulation in patients with chronic active hepatitis $\mathrm{C}$ : prevalence and role of hemochromatosis gene mutations and relationship with hepatitis histological lesions. J Hepatol 31:979-984

Holtzman NA, Elliot DA, Heller RH (1986) Copper intoxication: report of a case with observations on ceruloplasmin. N Engl J Med 275:347-352

Horslen SP, Tanner MS, Lyon TDB et al (1994) Copper associated childhood cirrhosis. Gut 35:1497-1500

Hsu CH, Yang SA, Wang JY, Yu HS, Lin SR (1999) Mutational spectrum of $\mathrm{p} 53$ gene in arsenic-related skin cancers from the blackfoot disease endemic area of Taiwan. Br J Cancer 80:1080-1086

Hughes JM, Weill H (1991) Asbestosis as a precursor of asbestos related lung cancer: results of a prospective mortality study. Br J Ind Med 48:229-233

Hume L, Roe M (1992) The biodurability of chrysotile asbestos. Am Mineral 77:1125-1128

Hunter D, Russell DS (1954) Focal cerebral and cerebellar atrophy in a human subject due to organic mercury compounds. J Neurol Neurosurg Psychol 17:235-241

Hutchinson J (1888) On some examples of arsenic-keratosis of the skin and arsenic-cancer. Trans Pathol Soc Lond 39:352-363

Huttunen JK (1997) Selenium and cardiovascular diseases — an update. Biomed Environ Sci 10:220-226

Iribarren C, Sempos CT, Eckfeldt JH, Folsom AR (1998) Lack of association between ferritin level and measures of LDL oxidation: the ARIC study. Atherosclerosis risk in communities. Atherosclerosis 139:189-195

James JA (1970) Acute iron poisoning: assessment of severity and prognosis. J Pediatr 77:117-119

Jensen S, Jernelov A (1969) Biological methylation of mercury in aquatic organisms. Nature 223:753-756

Jhaveri SS (1959) A case of cirrhosis and primary carcinoma of the liver in chronic arsenical intoxication. $\mathrm{Br} \mathrm{J}$ Ind Med $16: 248-250$

Jingbo PI, Hiroshi Y, Yoshito K, Guifan S, Takahiko Y, Hiroyuki A, Claudia HR, Nobuhiro S (2002) Evidence for induction of oxidative stress caused by chronic exposure of Chinese residents to arsenic 
contained in drinking water. Environ Health Perspect 110 (4):331-336

Johnson RA, Baker SS, Fallon JT, Maynard EP 3rd, Ruskin JN, Wen Z, Ge K, Cohen HJ (1981) An occidental case of cardiomyopathy and selenium deficiency. N Engl J Med 304:1210-1212

Joshi VV (1987) Indian childhood cirrhosis. Perspect Paediatr Pathol 11:175-192

Kageyama F, Kobayashi Y, Kawasaki T et al (2000) Successful interferon therapy reverses enhanced hepatic iron accumulation and lipid peroxidation in chronic hepatitis C. Am J Gastroenterol 95:1041-1050

Kardinaal AF, Kok FJ, Kohlmeier L, Martin-Moreno JM, Ringstad J, Gomez-Aracena J, Mazaev VP, Thamm M, Martin BC, Aro A, Kark JD, Delgado-Rodriguez M, Riemersma RA, van't Veer P, Huttunen JK (1997) Association between toenail selenium and risk of acute myocardial infarction in European men. The EURAMIC study. European antioxidant myocardial infarction and breast cancer. Am J Epidemiol 145:373-379

Kesteloot H, Roelandt J, Willems J, Class JM, Joosens JV (1968) An inquiry into the role of cobalt in the heart disease of chronic beer drinkers. Circulation 37:854-864

Kew J, Morris C, Aihie A et al (1993) Arsenic and mercury intoxication due to Indian ethnic remedies. Br Med J 306:506-507

Kiechl S, Willeit J, Egger G, Poewe W, Oberhollenzer F (1997) Body iron stores and the risk of carotid atherosclerosis: prospective results from the Bruneck study. Circulation 96:3300-3307

Kitchin KT (2001) Recent advances in arsenic carcinogenesis: modes of action, animal model systems, and methylated arsenic metabolites. Toxicol Appl Pharmacol 172(3):249-261

Koch P, Bahmer FA (1999) Oral lesions and symptoms related to metals used in dental restorations: a clinical, allergological, and histologic study. J Am Acad Dermatol 42:422-430

Kopp SJ, Barron JT, Tow JP (1988) Cardiovascular actions of lead and relationship to hypertension: a review. Environ Health Perspect 78:91-99

Krenzelok EP, Hoff JV (1979) Accidental iron poisoning: a problem of marketing and labeling. Pediatrics 63:591-596

Labadie H, Stoessel P, Callard P, Beaugrand M (1990) Hepatic venoocclusive disease and perisinusoidal fibrosis secondary to arsenic poisoning. Gastroenterology 99:1140-1143

Lansdown A (1995) Physiological and toxicological changes in the skin resulting from the action and interaction of metal ions. Crit Rev Toxicol 25:397-462

Lefkowitch JH, Honig CL, King ME, Hagstrom JWC (1982) Hepatic copper overload and features of Indian childhood cirrhosis in an American sibship. N Engl J Med 307:271-277

Li Y, Nan BS (1989) Correlation of selenium, glutathione peroxidase activity and lipoperoxidation rates in dilated cardiomyopathy. Chin Med J 102:670-671

Li JH, Rossman TC (1989) Inhibition of DNA ligase activity by arsenite: a possible mechanism of its comutagenesis. Mol Toxicol 2:1-9

Li GS, Wang F, Kang D, Li C (1985) Keshan disease: an endemic cardiomyopathy in China. Hum Pathol 16:602-609

Ludwig J, Farr GH, Freese DK, Sternlieb I (1995) Chronic hepatitis and hepatic failure in a 14-year-old girl. Hepatology 22:1874-1879

Ludwig J, Hashimoto E, Poroyko MD et al (1997) Hemosiderosis in cirrhosis: a study of 447 native livers. Gastroenterology 112:888-890

Lunchtrath H (1972) Cirrhosis of the liver in chronic arsenical poisoning of vintners. Ger Med Mon 2:127-128

Maggiore G, De Giacomo C, Sessa F, Burgio GR (1987) Idiopathic hepatic copper toxicosis in a child. J Pediatr Gastroenterol Nutr 6:980-983

Maheswaran R, Morris S, Falconer S, Grossinho A, Perry I, Wakefield J, Elliott P (1999) Magnesium in drinking water supplies and mortality from acute myocardial infarction in north west England. Heart 82:455-460

Mahon NG, Coonar AS, Jeffery S, Coccolo F, Akiyu J, Zal B, Houlston R, Levin GE, Baboonian C, McKenna WJ (2000) Haemochromatosis gene mutations in idiopathic dilated cardiomyopathy. Heart 84:541-547

Maloney M (1996) Arsenic in dermatology. Dermatol Surg 22:301-304

Mandishona E, MacPhail AP, Gordeuk VR et al (1998) Dietary iron overload as a risk factor for hepatocellular carcinoma in black Africans. Hepatology 27:1563-1566

Markesbery WR (1997) Oxidative stress hypothesis in Alzheimer's disease. Free Radic Biol Med 23:134-147

Marsh D (1979) Organic mercury: methylmercury compounds. In: Vinken PJ, Bryun GW (eds) Handbook of clinical neurology, vol 36. North-Holland, Amsterdam, pp 73-81

Mazumder DNG, Chakraborty AK, Ghosh A et al (1988) Chronic arsenic toxicity from drinking tube well water in rural West Bengal. Bull WHO 66:499-506

McDonald JC (1980) Asbestos and lung cancer: has the case been proven? Chest 78:374-376

McDonald A, McDonald J (1987) Epidemiology of malignant mesothelioma. In: Antman K, Aisner J (eds) Asbestos-related malignancy. Harcourt Brace Jovanovich, Orlando

Mena I (1979) Manganese poisoning. In: Vinken PJ, Bryun GW (eds) Handbook of clinical neurology, vol 36. North-Holland, Amsterdam, pp 217-237

Mena I et al (1967) Chronic manganese poisoning: clinical picture and manganese turnover. Neurology 17:128-136

Mendis S (1989) Magnesium, zinc, and manganese in atherosclerosis of the aorta. Biol Trace Elem Res 22:251-256

Meyers DG (1996) The iron hypothesis-does iron cause atherosclerosis? Clin Cardiol 19:925-929

Modell CB (1975) Transfusional haemochromatosis. In: Kief H (ed) Iron metabolism and its disorders. Excerpta Medica, Amsterdam, pp 230-239

Monoguerra AS (1976) Iron poisoning: report of a fatal case in an adult. Am J Hosp Pharmacol 33:1088-1090

Morgan A (1980) Effect of length on the clearance of fibers from the lung and on body formation. In: Wagner $\mathbf{J}$ (ed) Biologic effects of mineral fibers. International Agency for Research on Cancer, Lyon

Morgan A, Holmes A (1980) Concentrations and dimensions of coated and uncoated asbestos fibres in the human lung. $\mathrm{Br} \mathrm{J}$ Ind Med $37: 25-32$

Morgan A, Holmes A (1985) The enigmatic asbestos body: its formation and significance in asbestos-related disease. Environ Res 38:283-292

Morgan W, Seaton A (1975) Occupational lung diseases. W. B. Saunders, Philadelphia

Muehrcke RC, Pirani CL (1968) Arsine-induced anuria: a correlative clinicopathological study with electron microscopic observations. Ann Intern Med 68(4):853-866

Müller T, Feichinger H, Berger H, Muller W (1996) Endemic Tyrolean infantile cirrhosis: an ecogenetic disease disorder. Lancet 347:877-880

Müller-Höcker J, Meyer U, Wiebecke B, Hübner G (1985) Copper storage disease of the liver and chronic dietary copper intoxication in two further German infants mimicking Indian childhood cirrhosis. Pathol Res Pract 183:39-45

Müller-Höcker J, Weib M, Meyer U et al (1987) Fatal copper storage disease of the liver in a German infant resembling Indian childhood cirrhosis. Virchows Arch (A) 411:379-385

Murphy G (1995) Skin. In: Craighead J (ed) Pathology of environmental and occupational disease. Mosby, St. Louis, pp 437-453 
Murphy M, Hunt S, McDonald GSA et al (1991) Intrahepatic cholestasis secondary to gold therapy. Eur $\mathrm{J}$ Gastroenterol Hepatol 3:855-859

Nakamuro K, Sayato Y (1981) Comparative studies of chromosomal aberration induced by trivalent and pentavalent arsenic. Mutat Res 88:73-80

Narang R, Ridout D, Nonis C, Kooner JS (1997) Serum calcium, phosphorus and albumin levels in relation to the angiographic severity of coronary artery disease. Int J Cardiol 60:73-79

Navarro-Alarcon M, Lopez-Garcia de la Serrana H, Perez-Valero V, Lopez-Martinez C (1999) Serum and urine selenium concentrations in patients with cardiovascular diseases and relationship to other nutritional indexes. Ann Nutr Metab 43:30-36

Needleman HL (1988) The persistent threat of lead: medical and sociological issues. Curr Probl Pediatr 18:697-744

Needleman HL, Gunnoe C, Leviton A (1979) Deficits in psychologic and classroom performance in children with elevated dentine lead levels. N Engl J Med 300:689-695

Needleman HL, Schell A, Bellinger D (1990) The long-term effects of exposure to low doses of lead in childhood. An 11th year follow-up report. N Engl J Med 322:83-88

Neve J (1996) Selenium as a risk factor for cardiovascular diseases. J Cardiovasc Risk 3:42-47

Newland MC et al (1989) Visualizing manganese in the primate basal ganglia with magnetic resonance imaging. Eur Neurol 11106:251-258

Nightingale SL (1997) Action to prevent accidental iron poisonings in children. JAMA 277:1343

O’Neill NC, Tanner MS (1989) Uptake of copper from brass vessels in bovine milk and its relevance to Indian childhood cirrhosis. J Pediatr Gastroenterol Nutr 9:167-172

Olanow CW et al (1994) Manganese-induced neurotoxicity. In: Mizuno Y, Calne DB, Horowski R (eds) Advances in research on neurodegeneration. Vol II. Etiopathogenesis. Birkhauser, Boston, pp 53-62

Olanow CW et al (1996) Manganese intoxication in the rhesus monkey: a clinical, imaging, pathologic, and biochemical study. Neurology 46:492-498

Oliver RAM (1959) Siderosis following transfusions of blood. J Pathol Bacteriol 77:171-194

Oster O (1993) Trace element concentrations $(\mathrm{Cu}, \mathrm{Zn}, \mathrm{Fe})$ in sera from patients with dilated cardiomyopathy. Clin Chim Acta 214:209-218

Oster O, Prellwitz W (1990) Selenium and cardiovascular disease. Biol Trace Elem Res 24:91-103

Patrizi A, Rizzoli L, Vincenzi C, Trevisi P, Tosti A (1999) Sensitization to thimerosal in atopic children. Contact Dermat 40:94-97

Perl DP, Brody AR (1980) Alzheimer's disease: X-ray spectrographic evidence of aluminum accumulation in neurofibrillary tanglebearing neurons. Science 208:297-299

Perl DP, Good PF (1992) Aluminum and the neurofibrillary tangle: results of tissue microprobe studies. In: Williams RMP (ed) Ciba symposium: aluminum in biology and medicine. Wiley, New York, pp 217-236

Pestaner JP, Ishak KG, Mullick FG, Centeno J (1999) Ferrous sulfate toxicity: a review of autopsy findings. Biol Trace Elem Res 70:1-8

Pimental JC, Menezes AP (1977) Liver disease in vineyard sprayers. Gastroenterology 72:275-289

Pirisi M, Scott CA, Avellini C et al (2000) Iron deposition and progression of disease in chronic hepatitis C. Role of interface hepatitis, portal inflammation, and HFE missense mutations. Am J Clin Pathol 113:546-554

Raines DA, Kinsara AJ, Eid Fawzy M, Vasudevan S, Mohamed GE, Legayada ES, Al-Rawithi S, El-Yazigi A (1999) Plasma and urinary selenium in Saudi Arabian patients with dilated cardiomyopathy. Biol Trace Elem Res 69:59-68
Ramirez P, Eastmond DA, Laclette JP, Ostrosky-Wegman P (1997) Disruption of microtubule assembly and spindle formation for the induction of aneuploid cells by sodium arsenite and vanadium pentoxide. Mutat Res 386:291-298

Rauramaa R, Vaisanen S, Mercuri M, Rankinen T, Penttila I, Bond MG (1994) Association of risk factors and body iron status to carotid atherosclerosis in middle-aged eastern Finnish men. Eur Heart $\mathbf{J}$ 15:1020-1027

Rayman MP (2000) The importance of selenium to human health. Lancet 356:233-241

Reusche E, Koch V, Friedrich HJ, Nunninghoff D, Stein P, Rob PM (1996) Correlation of drug-related aluminum intake and dialysis treatment with deposition of argyrophilic aluminum-containing inclusions in CNS and in organ systems of patients with dialysisassociated encephalopathy. Clin Neuropathol 15:342-347

Riggio O, Montagnese F, Fiore P et al (1997) Iron overload in patients with chronic viral hepatitis: how common is it? Am J Gastroenterol 92:1298-1301

Roberts G (1971) The pathology of parietal pleural plaques. J Clin Pathol 24:348-353

Roggli V (1989) Pathology of human asbestosis: a critical review. In: Fenoglio-Preiser C (ed) Advances in pathology. Year Book Medical Publishers, Chicago

Roggli V (1992) Asbestos bodies and nonasbestos ferruginous bodies. In: Roggli V, Greenberg S, Pratt P (eds) Pathology of asbestosrelated disease. Little Brown \& Company, Boston

Roggli V (1994) The pneumoconioses: asbestosis. In: Saldana M (ed) Pathology of pulmonary disease. J. B. Lippincott, Philadelphia

Roggli V, Pratt P (1983) Numbers of asbestos bodies on iron-stained sections in relation to asbestos body counts in lung tissue digests. Hum Pathol 14:355-361

Roggli V, Pratt P (1992) Asbestosis. In: Roggli V, Greenberg S, Pratt P (eds) Pathology of asbestos-associated diseases. Little Brown \& Company, Boston

Roggli V, Shelburne J (1994) Pneumoconioses, mineral and vegetable. In: Dail D, Hammar S (eds) Pulmonary pathology. Springer, New York

Rosenberg HG (1974) Systemic arterial disease and chronic arsenicism in infants. Arch Pathol 97:360-365

Rubenowitz E, Axelsson G, Rylander R (1999) Magnesium and calcium in drinking water and death from acute myocardial infarction in women. Epidemiology 10:31-36

Russell M, Langley M, Truett A, King L, Boyd A (1997) Lichenoid dermatitis after consumption of gold-containing liquor. J Am Acad Dermatol 36:841-844

Salonen JT, Alfthan G, Huttunen JK, Pikkarainen J, Puska P (1982) Association between cardiovascular death and myocardial infarction and serum selenium in a matched-pair longitudinal study. Lancet 2:175-179

Salonen JT, Salonen R, Seppanen K, Kantola M, Parviainen M, Alfthan G, Maenpaa PH, Taskinen E, Rauramaa R (1988) Relationship of serum selenium and antioxidants to plasma lipoproteins, platelet aggregability and prevalent ischaemic heart disease in eastern Finnish men. Atherosclerosis 70:155-160

Salonen JT, Seppanen K, Lakka TA, Salonen R, Kaplan GA (2000) Mercury accumulation and accelerated progression of carotid atherosclerosis: a population-based prospective 4-year follow-up study in men in eastern Finland. Atherosclerosis 148:265-273

Salvini S, Hennekens CH, Morris JS, Willett WC, Stampfer MJ (1995) Plasma levels of the antioxidant selenium and risk of myocardial infarction among U.S. Physicians. Am J Cardiol 76:1218-1221

Sanchez-Fructuoso AI, Torralbo A, Arroyo M, Luque M, Ruilope LM, Santos JL, Cruceyra A, Barrientos A (1996) Occult lead intoxication as a cause of hypertension and renal failure. Nephrol Dial Transplant 11:1775-1780 
Schafer AI, Cheron RG, Dluchy R et al (1981) Clinical consequences of acquired transfusional iron overload in adults. $\mathrm{N}$ Engl $\mathrm{J}$ Med 304:319-324

Scheinberg IH, Sternlieb I (1994) Is non-Indian childhood cirrhosis caused by excess dietary copper? Lancet 344:1002-1004

Schoolmeester WL, White DR (1980) Arsenic poisoning. South Med J 73:198

Schramel P, Müller-Höcker J, Meyer U et al (1988) Nutritional copper intoxication in three carcinoma infants with severe liver cell damage (features of Indian childhood cirrhosis). J Trace Elem Electrolyte Health Dis 2:85-89

Schumann K (2001) Safety aspects of iron in food. Ann Nutr Metab 45:91-101

Searle J, Leggett BA, Crawford DHG, Powell LW (2001) Iron storage disease. In: MacSween RNM, Burt AD, Portmann BC, Ishak KG, Scheuer PJ, Anthony PP (eds) Pathology of the liver. Churchill Livingstone, London, pp 257-272

Selikoff IJ, Hammond EC, Seidman H (1980) Latency of asbestos disease among insulation workers in the United States and Canada. Cancer 46:2736-2740

Sempos CT, Looker AC, Gillum RE, McGee DL, Vuong CV, Johnson CL (2000) Serum ferritin and death from all causes and cardiovascular disease: the NHANES II mortality study. National health and nutrition examination study. Ann Epidemiol 10:441-448

Shiono Y, Wakusawa S, Hayashi H et al (2001) Iron accumulation in the liver of male patients with Wilson's disease. Am J Gastroenterol 96:3147-3151

Shiraki H (1979) Neuropathological aspects of organic mercury intoxication, including Minamata disease. In: Vinken PJ, Bryun GW (eds) Handbook of clinical neurology, vol 36. North-Holland, Amsterdam, pp 83-145

Simeonova PP, Luster MI (2000) Mechanisms of arsenic carcinogenicity: genetic or epigenetic mechanisms. J Environ Pathol Toxicol Oncol 19:281-286

Sluis-Cremer GK, Bezuidenhout BN (1989) Relation between asbestosis and bronchial cancer in amphibole asbestos miners (see comments). Br J Ind Med 46:537-540

Smetana HF, Hadley GG, Sirsat SM (1961) Infantile cirrhosis. An analytic review of the literature and a report of 50 cases. Pediatrics 28:107-127

Sokas RK, Simmens S, Sophar K, Welch LS, Liziewski T (1997) Lead levels in Maryland construction workers. Am J Ind Med 31:188-194

Spitainy KC, Brondum J, Vogt RL et al (1984) Drinking-water-induced copper intoxication in a Vermont family. Pediatrics 74:1103-1106

Staessen JA, Bulpitt CJ, Fagard R, Lauwerys RR, Roels H, Thijs L, Amery A (1994) Hypertension caused by low-level lead exposure: myth or fact? J Cardiovasc Risk 1:87-97

Staessen JA, Roels H, Fagard R (1996) Lead exposure and conventional and ambulatory blood pressure: a prospective population study. PheeCad investigators. J Am Med Assoc 275:1563-1570

Styblo M, Drobna Z, Jaspers I, Lin S, Thomas DJ (2002) The role of biomethylation in toxicity and carcinogenicity of arsenic: a research update. Environ Health Perspect 110(5):767-771

Suadicani P, Hein HO, Gyntelberg F (1992) Serum selenium concentration and risk of ischaemic heart disease in a prospective cohort study of 3000 males. Atherosclerosis 96:33-42

Tanner MS, Kantarjian AH, Bhave SA, Pandit AN (1983) Early introduction of copper-contaminated animal milk feed as a possible cause of Indian childhood cirrhosis. Lancet 2:992-995
Tanner MS, Bhave SA, Prodham AM, Pandit AN (1987) Clinical trials of penicillamine in Indian childhood cirrhosis. Arch Dis Child 62:118-1124

Tchounwou PB, Wilson BA, Schneider J, Ishaque A (2000) Cytogenetic assessment of arsenic trioxide toxicity in the mutatox, Ames II, and CAT-Tox assays. Met Ions Biol Med 6:89-91

Tchounwou PB, Wilson BA, Ishaque A, Schneider J (2001) Atrazine potentiation of arsenic trioxide-induced cytotoxicity and gene expression in human liver carcinoma cells (HepG2). Mol Cell Biochem 222:49-259

Timbrell V, Pooley F, Wagner J (1970) Characteristics of respirable asbestos fibers. In: Shaprio H (ed) Pneumoconioses: proceedings of the international conference, Johannesburg. Oxford University Press, London

Tsai S, Wang T, Ko Y (1999) Mortality for certain diseases in areas with high levels of arsenic in drinking water. Arch Environ Health 54:186-193

Turlin B, Juguet F, Moirand R et al (1995) Increased liver iron stores in patients with hepatocellular carcinoma developed on a noncirrhotic liver. Hepatology 22:446-450

Van Glahn WC, Flinn FB, Keim WF (1938) Effect of certain arsenates on the liver. Arch Pathol 25:488-505

Van Heck E, Kint A, Temmerman L (1981) A lichenoid eruption induced by penicillamine. Arch Dermatol 117:676

Vijaya J, Subramanyam G, Sukhaveni V, Abdul Latheef SA, Gupta SR, Sadhasivaiah G, Salam NM (2000) Selenium levels in dilated cardiomyopathy. J Indian Med Assoc 98:166-169

Virtamo J, Valkeila E, Alfthan G, Punsar S, Huttunen JK, Karvonen MJ (1985) Serum selenium and the risk of coronary heart disease and stroke. Am J Epidemiol 122:276-282

Wagner J, Newhouse M, Corrin B et al (1988) Correlation between fibre content of the lung and disease in east London factory workers. $\mathrm{Br} \mathrm{J}$ Indust Med 45:305-308

Wei M, Wanibuchi H, Morimura K, Iwai S, Yoshida K, Endo G, Nakae D, Fukushima S (2002) Carcinogenicity of dimethylarsinic acid in male F344 rats and genetic alterations in induced urinary bladder tumors. Carcinogenesis 23(8):1387-1397

Westlin WF (1966) Deferoxamine in the treatment of acute iron poisoning. Clinical experiences with 172 children. Clin Pediatr 5:531

Wright J, Churg A (1998) Diseases caused by gases and fumes. In: Churg A, Green F (eds) Pathology of occupational lung disease. Williams \& Wilkins, Baltimore

Yang FY, Lin ZH, Li SG, Guo BQ, Yin YS (1988) Keshan disease-an endemic mitochondrial cardiomyopathy in China. J Trace Elem Electrolyte Health Dis 2:157-163

Yegin A, Yegin H, Aliciguzel Y, Deger N, Semiz E (1997) Erythrocyte selenium-glutathione peroxidase activity is lower in patients with coronary atherosclerosis. Jpn Heart J 38:793-798

Yelin G, Taff ML, Sadowski GE (1987) Copper toxicity following massive ingestion of coins. Am J Forensic Med Pathol 8:78-85

Younossi ZM, Gramlich T, Bacon BR et al (1999) Hepatic iron and nonalcoholic fatty liver disease. Hepatology 30:847-850

Zenker F (1867) Iron lung: sclerosis pulmonum. Dtsch Arch Klin Med 2:116

Zielhuis R (1977) Public health risks of asbestosis. Pergamon Press, Elmsford 